\title{
Advanced oxidation processes for the removal of cyanobacterial toxins from drinking water
}

\author{
Marcel Schneider ${ }^{*}$ (ID and Luděk Bláha
}

\begin{abstract}
Drinking water production faces many different challenges with one of them being naturally produced cyanobacterial toxins. Since pollutants become more abundant and persistent today, conventional water treatment is often no longer sufficient to provide adequate removal. Among other emerging technologies, advanced oxidation processes (AOPs) have a great potential to appropriately tackle this issue. This review addresses the economic and health risks posed by cyanotoxins and discusses their removal from drinking water by AOPs. The current state of knowledge on AOPs and their application for cyanotoxin degradation is synthesized to provide an overview on available techniques and effects of water quality, toxin- and technique-specific parameters on their degradation efficacy. The different AOPs are compared based on their efficiency and applicability, considering economic, practical and environmental aspects and their potential to generate toxic disinfection byproducts. For future research, more relevant studies to include the degradation of less-explored cyanotoxins, toxin mixtures in actual surface water, assessment of residual toxicity and scale-up are recommended. Since actual surface water most likely contains more than just cyanotoxins, a multi-barrier approach consisting of a series of different physical, biological and chemical — especially oxidativetreatment steps is inevitable to ensure safe and high-quality drinking water.
\end{abstract}

Keywords: AOP, Cyanotoxin, Cylindrospermopsin, Fenton oxidation, Hydroxyl radical, Microcystin, Ozone, Sulfate radical, UV, Water treatment

\section{Background}

Cyanobacteria are the most diverse and widespread phototrophic prokaryotes inhabiting earth for several billions of years $[1,2]$. Cyanobacteria can be found almost everywhere in terrestrial and aquatic environments, even in Antarctic lakes and hot springs [3]. Due to their dependence on nutrients and temperature, the increasing eutrophication of waterbodies and climate change promote more frequently and extensively occurring cyanobacterial blooms $[2,4-6]$. Although not all blooms are poisonous, at least 40 cyanobacterial species are known to produce diverse secondary metabolites that are toxic

\footnotetext{
*Correspondence: marcel.schneider@recetox.muni.cz; marcel. schneider90@outlook.com

RECETOX, Faculty of Science, Masaryk University, Kamenice 753/5,
} 62500 Brno, Czech Republic to biota including plants [7], animals and humans. Consequently, cyanobacteria and their toxins pose a major risk to surface waters intended for drinking and recreational purposes, and adequate measures must be employed to prevent or eliminate cyanobacterial blooms and toxins.

The first approach should prevent the occurrence of cyanobacterial blooms in surface water by measures such as nutrient reduction, biomanipulation or the application of algaecides $[4,8]$. Importantly, especially in the case of toxic cyanobacteria, the removal of intact cyanobacterial cells is essential to avoid the release of intracellular toxins, e.g., microcystins (MCs), anatoxin-a (ANTX) and saxitoxin (STX) [6, 9].

The second approach is the removal of cyanobacterial cells and metabolites in drinking water treatment facilities. Although most conventional drinking water 
treatment methods effectively remove cyanobacterial cells and intracellular metabolites, extracellular and dissolved cyanotoxins may bypass conventional methods such as rapid sand filtration and coagulation [2]. Hence, adequate and more advanced treatment measures must be implemented to ensure sufficient removal of cyanotoxins. While traditional treatment approaches such as physical retention, biodegradation or chemical oxidation can be effective, they all come with various practical, economic or environmental disadvantages.

Toxin removal by physical retention can be achieved by filter membranes with very low molecular weight cutoff pore sizes, i.e., nanofiltration and reverse osmosis, or adsorbents like activated carbon and bioadsorbents [10]. However, when dissolved cyanotoxins are only physically removed, appropriate measures for the disposal or further treatment of the toxin-enriched retentate are required. In addition, filter beds and membranes may need to be backwashed regularly to prevent clogging, fouling and cyanobacterial growth on the filter medium $[10,11]$.

Although several cyanotoxins are biodegradable [12], their periodical occurrence may limit the microorganisms' ability to degrade cyanotoxins, resulting in an initial lag-phase of up to a few days without pre-conditioning $[10,12]$. Moreover, most enzymatic degradation mechanisms are still poorly understood which makes it difficult to predict the effectiveness of a biological treatment barrier $[10,12]$ and potential drawbacks such as the biotransformation of the less-toxic gonyautoxin (GTX) into the more toxic STX [12].

Although commonly used oxidants such as chlorine and permanganate effectively degrade some cyanotoxins, others are not susceptible or require oxidant concentrations and reaction times that are substantially higher than those usually applied in drinking water treatment $[2$, $9,13]$. As a major disadvantage, chlorination can produce halogenated disinfection byproducts formed from the reaction of chlorine with organic matter or in the presence of bromide [14]. Furthermore, residual chlorine may impair the drinking water quality due its possibly perceptible taste and odor. Permanganate on the other hand does neither promote the formation of toxic disinfection byproducts, nor produce taste or odor, but it tints the water pink at $>0.05 \mathrm{mg} \mathrm{L}^{-1}$, which limits its application and residual concentration in drinking water [10].

As another form of oxidation, advanced oxidation processes (AOPs) have received a lot of attention for their application in drinking and wastewater treatment for the degradation of even recalcitrant organic compounds and disinfection of pathogens. In AOPs, reactive species, mainly $\cdot \mathrm{OH}$, and other mechanisms are formed in situ [10]. This review gives a detailed insight into AOPs which were investigated for cyanotoxin removal from drinking water to evaluate their feasibility and applicability. Therefore, we briefly outline current regulations for cyanotoxins in drinking water and basic principles of different AOPs. Following, we discuss the most relevant findings from the scientific literature on the degradation effectiveness, advantages and disadvantages of individual methods and the role of relevant water quality parameters. From there, information gaps are identified and recommendations for future research for the effective removal of cyanotoxins from drinking water are formulated.

\section{Cyanobacterial toxins}

Cyanotoxins can cause a vast range of clinical signs, including acute hepatotoxicosis, peracute neurotoxicosis, gastrointestinal disturbances as well as respiratory and allergic reactions [6]. Many different cyanobacterial metabolites can be considered cyanotoxins [15]. Here, we will only focus on cyanotoxins for which information on their removal from drinking water was found.

\section{Microcystins}

Microcystins are the most commonly studied cyanotoxins produced by different cyanobacteria such as Microcystis, Nostoc, Planktothrix and many other species [16]. This group of water soluble cyclic heptapetides consists of more than 100 congeners which exhibit similar toxicological properties due to their akin chemical structure, which mainly differs in two amino acids $X$ and $Z$ (Fig. 1) [6]. Hence, MCs are named according to these two variable amino acids, e.g., MC-LR with $X$ and $Z$ being leucine (L) and arginine (R), respectively. The hydrophobic Adda amino acid is often associated as the key structural element for MCs' biological activity [14]. Unless cyanobacterial cells lyse due to extrinsic stress or senescence, MCs are usually intracellular. In the presence of bacteria and photosynthetic pigments, dissolved MCs rapidly degrade in natural waters [6]. Depending on the degree of sunlight, content of natural organic matter (NOM) and presence of bacteria, MCs can have a half-life of 4 to 14 days in surface water [17].

\section{Nodularin}

Nodularin (NOD) and its seven analogs are cyclic pentapeptides produced by Nodularia and Nostoc strains. NOD's structure (Fig. 1) is similar to MC, leading to similar chemical and toxicological characteristics $[6,16]$. Similar to MC, the hepatotoxic NOD is also intracellular until the bloom starts to decay [6].

\section{Cylindrospermopsin}

Cylindrospermopsin (CYN) was first isolated from Cylindrospermopsis raciborskii and later from other species 


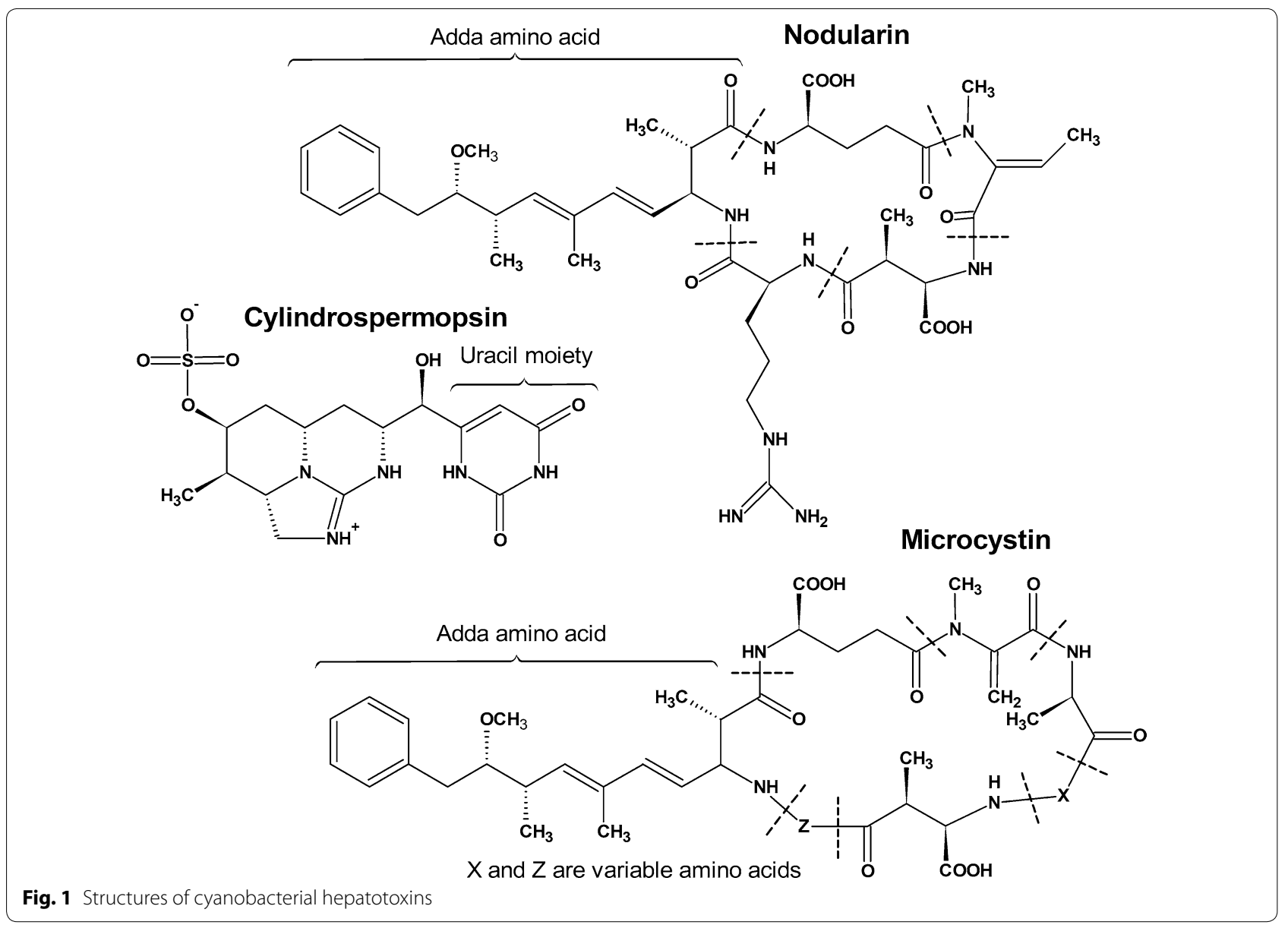

including Aphanizomenon and Oscillatoria. So far, five analogs of this highly water soluble and planar-shaped alkaloid have been described (Fig. 1) [18, 19]. CYN is extracellular and is relatively stable to a wide range of heat, light and $\mathrm{pH}$ conditions. The alkaloid can persist in water for more than a month $[6,18]$. However, when exposed to sunlight in the presence of cell pigments, CYN has a half-life of about 0.6 to 0.9 days [17].

\section{Anatoxins}

Anatoxin-a (Fig. 2) and its derivatives are produced by Aphanizomenon, Dolichospermum (formerly Anabaena), Oscillatoria and Planktothrix. The extremely potent alkaloid neurotoxin acts as a cholinergic nicotinic agonist causing nerve depolarization and neuromuscular blockage. ANTX is usually intracellular, but rapidly degrades once it is released from cells and is exposed to natural sunlight (half-life of approximately $100 \mathrm{~min}$ ) and oxidants. However, in the absence of sunlight, ANTX can reach a half-life of several days to months. Main degradation products of ANTX and homoanatoxin-a are the notably less-toxic dihydro- and epoxy analogs $[9,17,20]$.

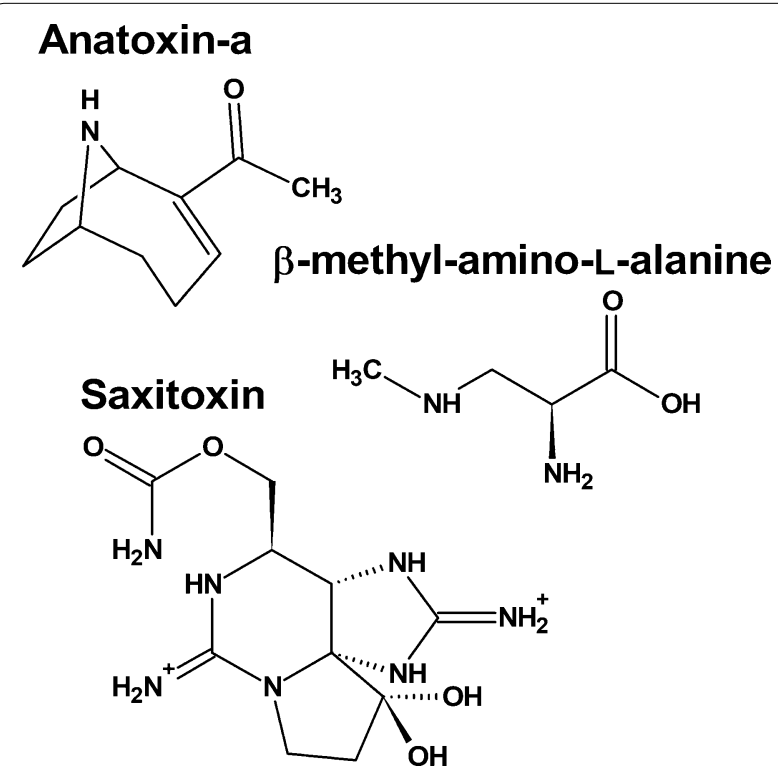

Fig. 2 Structures of cyanobacterial neurotoxins 


\section{Saxitoxins}

STX, also known as paralytic shellfish toxin, is produced by organisms from different taxonomic kingdomseukaryotic dinoflagellates and prokaryotic cyanobacteria. Cyanobacterial producers include Aphanizomenon, Cylindrospermopsis, Dolichospermum and Lyngbya [21]. STX can be substituted at various positions (Fig. 2), resulting in currently 57 known analogs, which can be grouped into non-sulphated STXs, singly sulfated GTXs and doubly sulfated C-toxins. The toxicity of the STXs analogs inversely increases with the number of substituted sulfates $[12,21]$. Because of its two cationic guanidine groups, the alkaloid is water soluble [9]. Unless cyanobacterial cells lyse, STX is usually intracellular [9].

\section{$\beta-N$-methylamino-L-alanine}

$\beta$ - $N$-methylamino-L-alanine (BMAA) is a non-proteinogenic amino acid (Fig. 2) reported to be present in terrestrial and marine, free-living and plant symbiotic cyanobacteria including Aphanizomenon, Cylindrospermopsis, Microcystis and Nodularia [22]. The possible association of BMAA with several neurotoxic outcomes is discussed in the literature, e.g., by Ploux et al. [22] and references cited therein.

\section{Exposure to cyanobacterial toxins and current regulations for drinking water}

The presence of harmful cyanobacterial blooms and their toxins can evidently be traced back to the nineteenth century, where poisoning through ingestion of surface water led to sickness and death of livestock, pets and wildlife [23]. Ever since, cyanobacterial blooms and toxins have reportedly caused several, partly fatal incidents around the globe. In 1979, more than 100 people were poisoned and had to be hospitalized in Queensland, Australia due to the consumption of contaminated drinking water. Further investigations identified the water supply and later determined Cylindrospermopsis raciborskii as the source for the poisoning, which is now known as the Palm Island mystery disease [24]. Almost 20 years later, 76 hemodialysis patients died in Brazil due to the utilization of water contaminated with MCs and CYN for hemolysis treatment [25]. Besides posing a risk to human health, cyanotoxins can also have economic consequences [26]. Due to a massive Planktothrix rubescens bloom in the Serbian Vrutci reservoir with cell counts of about 10,000 cells $\mathrm{L}^{-1}$ in the treated drinking water in December 2013, Serbian authorities prohibited the use of tap water in the city of Užice, Serbia (approximately 70,000 inhabitants). As a result of the incapability to remove cyanobacterial cells and toxins, an alternative, cyanobacteria-free water source-Sušičko vrelo reservoir-had to be used for several years until reconstruction of the Vrutci reservoir treatment facility was completed [27]. In a similar, but more far-reaching incident, the Ohio EPA put a temporary ban on tap water for the city of Toledo, Ohio, USA in August 2014. About 500,000 people were advised not to drink or otherwise use tap water after MC concentrations in the drinking water exceeded the regulatory threshold of $1 \mu \mathrm{g} \mathrm{L}^{-1}$. After a few days, when MC concentrations decreased to below the limit, the ban was lifted [28, 29].

To protect humans from exposure to cyanotoxins through consumption of contaminated drinking water, adequate treatment measures must be employed. However, even if effective removal techniques are in place, a comprehensive drinking water guideline, containing a thorough monitoring and actions' program, is indispensable. A set of threshold values can thus help to take actions in case they are exceeded. So far, the WHO suggested a provisional guideline value (GV) for MC-LR of $1 \mu \mathrm{g} \mathrm{L}^{-1}$ based on a total daily intake (TDI) of $0.04 \mu \mathrm{g} \mathrm{kg}^{-1}$ day $^{-1}$ derived from acute toxicity data [30]. However, GVs for others cyanotoxins have not been proposed yet due to the lack of toxicological and epidemiological data. The upcoming update on the WHO Guidelines for Drinking-water Quality, to be published in 2020-2021, is expected to include recommendations for ANTX, CYN and STX as well as a revision of the GV for MC. Updates can be found on the homepage [31]. The currently proposed GV for MC-LR was accepted or adapted by many countries across the globe [32]. The lack of toxicological and epidemiological data on effects of exposure to other cyanotoxins also raises the question on effects from cyanotoxin mixtures and chronic exposure. The US EPA was the first to propose a chronic TDI $\left(0.003 \mu \mathrm{g} \mathrm{kg}^{-1} \mathrm{day}^{-1}\right)$ for MC-LR and lowered their acute TDI $\left(0.006 \mu \mathrm{g} \mathrm{kg}^{-1} \mathrm{day}^{-1}\right)$ based on updated data [16].

\section{AOPs for cyanotoxin removal from drinking water}

Although many different reactive chemical species can be produced, short-lived $\cdot \mathrm{OH}$ is often considered to be the most important species generated in AOPs in water, most likely due to its comparably high reactivity as indicated by its redox potential (Table 1). This non-selectively and randomly attacking oxidant primarily reacts with organic compounds in two distinctive mechanisms: (i) via an electrophilic attack at electron-rich moieties such as $\mathrm{C}=\mathrm{C}$ double bonds, aromatic systems and neutral amines, and (ii) via hydrogen abstraction from $\mathrm{C}-\mathrm{H}$ groups [33]. At neutral $\mathrm{pH}, \cdot \mathrm{OH}$ can also react in an often kinetically disfavored one-electron transfer mechanism [34].

The following sections address the existing knowledge on the removal of different cyanotoxins by AOPs in detail. We were able to identify studies that investigated the use of hydrogen peroxide, ozone, photolysis 
Table 1 Redox potentials of commonly used oxidants indicating their reactivity

\begin{tabular}{|c|c|c|}
\hline Oxidant & $\mathrm{pH}$ range & $\begin{array}{l}\text { Redox } \\
\text { potential } \\
\text { in V/SHE }\end{array}$ \\
\hline Sulfate radical $\left(\mathrm{SO}_{4}^{-}\right)$ & Acidic to neutral & $2.5-3.1^{\mathrm{a}}$ \\
\hline \multirow[t]{2}{*}{ Hydroxyl radical $(\cdot \mathrm{OH})$} & Acidic & $2.7^{\mathrm{a}}$ \\
\hline & Neutral to alkaline & $1.8^{\mathrm{a}}$ \\
\hline \multirow{2}{*}{ Ferrate $\left(\left[\mathrm{FeO}_{4}\right]^{2-}\right)$} & Acidic & $2.2^{b}$ \\
\hline & Alkaline & $0.7^{b}$ \\
\hline \multirow[t]{2}{*}{ Ozone $\left(\mathrm{O}_{3}\right)$} & Acidic & $2.1^{\mathrm{a}}$ \\
\hline & Alkaline & $1.2^{\mathrm{a}}$ \\
\hline Peroxydisulfate $\left(\mathrm{S}_{2} \mathrm{O}_{8}{ }^{2-}\right)$ & Acidic & $2.0^{\mathrm{a}}$ \\
\hline \multirow[t]{2}{*}{ Hydrogen peroxide $\left(\mathrm{H}_{2} \mathrm{O}_{2}\right)$} & Acidic & $1.8^{\mathrm{a}}$ \\
\hline & Alkaline & $0.9^{\mathrm{a}}$ \\
\hline $\begin{array}{l}\text { Peroxymonosulfate }\left(\mathrm{HSO}_{5}{ }^{-} \text {or }\right. \\
\left.\mathrm{SO}_{5}^{2-}, \mathrm{pK}_{\mathrm{a}}=9.4^{\mathrm{C}}\right)\end{array}$ & Acidic & $1.8^{\mathrm{a}}$ \\
\hline Hydroperoxy radical $\left(\mathrm{HO}_{2} \cdot\right)$ & - & $1.7^{\mathrm{d}}$ \\
\hline \multirow[t]{2}{*}{ Permanganate $\left(\mathrm{MnO}_{4}^{-}\right)$} & Acidic & $1.7^{\mathrm{a}}$ \\
\hline & Alkaline & $0.6^{\mathrm{a}}$ \\
\hline Hypochlorous acid (HOCl) & - & $1.5^{\mathrm{c}}$ \\
\hline Chlorine $\left(\mathrm{Cl}_{2}\right)$ & - & $1.4^{\mathrm{d}}$ \\
\hline Chlorine dioxide $\left(\mathrm{ClO}_{2}\right)$ & - & $1.3^{\mathrm{d}}$ \\
\hline Peroxymonosulfate radical $\left(\mathrm{SO}_{5}^{-}\right.$.) & Neutral & $1.1^{\mathrm{c}}$ \\
\hline Sulfite radical $\left(\mathrm{SO}_{3}^{-}\right.$.) & Neutral & $0.6^{c}$ \\
\hline
\end{tabular}

SHE standard hydrogen electrode

a [35]

b [10]

c [36]

${ }^{d}[13]$

(including the combination with oxidants and catalysts), Fenton oxidation, non-thermal plasmas, sulfate radicals, electrochemical oxidation, sonolysis and radiolysis.

\section{Hydrogen peroxide}

Although $\mathrm{H}_{2} \mathrm{O}_{2}$ has a higher redox potential than, e.g., chlorine under acidic conditions (Table 1) and is often used as a precursor for $\cdot \mathrm{OH}$ as well as to improve the effectiveness of AOPs, it is relatively ineffective for the degradation of cyanotoxins if employed solely. Removal of MC-LR, CYN, ANTX and BMAA by $\mathrm{H}_{2} \mathrm{O}_{2}$ was reported to be $<10 \%$ [37-41]. Even at $30{ }^{\circ} \mathrm{C}$ for $3.5 \mathrm{~h}$, only about 3\% MC-LR was removed by $\mathrm{H}_{2} \mathrm{O}_{2}$ [36].

\section{Ozonation and $\mathrm{O}_{3}$-based AOPs}

Ozonation is widely employed in drinking water treatment for disinfection of microorganisms and oxidation of various organic pollutants [42]. Even though ozonation itself technically is not an AOP as $\mathrm{O}_{3}$ is usually produced in the gaseous phase, we discuss it in this review, because $\mathrm{O}_{3}$ can be used as an AOP precursor and it decomposes to $\cdot \mathrm{OH}$ in situ under alkaline conditions (Eqs. 1 and 2) [2, 43]. Ozone itself has a relatively high redox potential at acidic $\mathrm{pH}$ (Table 1) and reacts with organic compounds in a similar but more selective manner compared to .OH. It attacks electron-rich groups such as unsaturated $\mathrm{C}=\mathrm{C}$, aromatic systems and neutral amines [9]. Numerous studies showed the high effectiveness of $\mathrm{O}_{3}$ for the degradation of MCs, NOD, CYN, ANTX and BMAA $[14,19,37,44-46])$. On the other hand, ozonation is not recommended for STXs degradation, as the toxicity to mice of an STX extract treated with $\mathrm{O}_{3}$ and $\mathrm{O}_{3} / \mathrm{H}_{2} \mathrm{O}_{2}$ was reduced by $<10 \%$ only [47].

$$
\begin{aligned}
& \mathrm{O}_{3}+\mathrm{OH}^{-} \rightarrow \mathrm{HO}_{2}^{-}+\mathrm{O}_{2} \\
& \mathrm{O}_{3}+\mathrm{HO}_{2}^{-} \rightarrow \cdot \mathrm{OH}+\mathrm{O}_{2}^{-} \cdot+\mathrm{O}_{2} \\
& \mathrm{Fe}^{2+}+\mathrm{O}_{3} \rightarrow \mathrm{FeO}^{2+}+\mathrm{O}_{2} \\
& \mathrm{FeO}^{2+}+\mathrm{H}_{2} \mathrm{O} \rightarrow \mathrm{Fe}^{3+}+\cdot \mathrm{OH}+\mathrm{OH}^{-} \\
& \mathrm{O}_{3}+\mathrm{O}_{2}^{-} \cdot \rightarrow \mathrm{O}_{3}^{-} \cdot+\mathrm{O}_{2} \\
& \mathrm{CO}_{3}^{2-}+\cdot \mathrm{OH} \rightarrow \mathrm{CO}_{3}^{-} \cdot+\mathrm{OH}^{-} \\
& \mathrm{HCO}_{3}^{-}+\cdot \mathrm{OH} \rightarrow \mathrm{CO}_{3}^{-} \cdot+\mathrm{H}_{2} \mathrm{O} \\
& \mathrm{O}_{3}+\cdot \mathrm{OH} \rightarrow \mathrm{HO}_{2} \cdot+\mathrm{O}_{2}
\end{aligned}
$$

Ozone can be used as an AOP precursor in combination with other oxidants, UV light (see the section on "Photolysis in combination with oxidants"), catalysts and adsorbents, which increase $\cdot \mathrm{OH}$ formation. One of the most commonly used and comparatively cheap $\mathrm{O}_{3}$-based AOPs is the peroxone process, in which $\mathrm{O}_{3}$ reacts with deprotonated $\mathrm{H}_{2} \mathrm{O}_{2}$ to produce $\cdot \mathrm{OH}$ (Eq. 2). This process has been shown to further increase the degradation of MCs and ANTX compared to $\mathrm{O}_{3}$ alone $[44,45]$. Similarly, degradation of both toxins also increased when $\mathrm{Fe}^{2+}$ was combined with $\mathrm{O}_{3}$ (Eqs. 3 and 4) [44, 45]. However, the combination of $\mathrm{O}_{3}$ with the Fenton's reagent (see the section on "Fenton oxidation") only improved MC-LR degradation at low $\mathrm{O}_{3}$ concentrations due to the oxidation of $\mathrm{Fe}^{2+}$ at higher levels [48]. Instead of $\mathrm{Fe}^{2+}$, the commonly used photocatalyst $\mathrm{TiO}_{2}$ can also be used. CYN degradation improved by almost $30 \%$ when $\mathrm{O}_{3}$ was combined with $\mathrm{TiO}_{2}$ due to increased $\mathrm{O}_{3}$ decomposition to $\cdot \mathrm{OH}$ and CYN adsorption to the catalyst [49].

With regard to water quality parameters, $\mathrm{pH}$ plays an important role because it can affect both the toxin speciation and the oxidant, influencing thus the treatment 
effectiveness. Although $\mathrm{O}_{3}$ reactivity with the conjugated diene in MCs' Adda amino acid was shown to be $\mathrm{pH}$-independent, reactions with the amine and uracil moiety in ANTX and CYN, respectively, depend on the $\mathrm{pH}$ in consistence with the toxins' $\mathrm{pK}_{\mathrm{a}}$ value $[14,19]$. In contrast, Al Momani et al. [45] observed a substantially reduced MC-LR degradation when increasing the $\mathrm{pH}$ from 2 to 11 . This indicates that not only toxin speciation, but also reactivity and availability of dissolved ozone are $\mathrm{pH}$-dependent. Under alkaline conditions, $\mathrm{O}_{3}$ redox potential decreases by almost $50 \%$ (Table 1 ) and ozone decomposition to $\cdot \mathrm{OH}$ increases (Eqs. 1, 2 and 5). In addition, if $\cdot \mathrm{OH}$ quenching by NOM and alkalinity (as carbonate/bicarbonate, Eqs. 6 and 7) is reduced due to low availability, ozone consumption is further promoted by $\cdot \mathrm{OH}$ (Eq. 8) [43]. BMAA degradation with $\mathrm{O}_{3}$ was also observed to be pH-dependent but direct $\mathrm{O}_{3}$ attack was less important, while secondary oxidants such as $\mathrm{HO}_{2}{ }^{-}$formed from $\mathrm{O}_{3}$ under alkaline conditions (Eq. 1) played a substantial role [37]. Moreover, the selectivity of $\mathrm{O}_{3}$ toward specific electron-rich moieties was shown to be $\mathrm{pH}$-dependent, as the $\mathrm{C}=\mathrm{C}$ double bonds in $\mathrm{CYN}$ and ATNX are primarily attacked at $\mathrm{pH}<7-8$, whereas oxidation of the amine groups dominates at higher $\mathrm{pH}[14,19$, 46]. Overall, reaction rate for the ozonation at $\mathrm{pH} 8$ was in the order of MC-LR > CYN > ANTX [19].

Besides $\cdot \mathrm{OH}$ quenching, NOM may also quench $\mathrm{O}_{3}$. In the presence of $2 \mathrm{mg} \mathrm{L}^{-1}$ humic acid, MC-LR and -RR degradation by $\mathrm{O}_{3}$ reduced by approximately $25 \%$ [45]. In fact, NOM concentration was shown to be more influential on the degradation than its composition and alkalinity $[19,49]$. In addition to water quality parameters discussed above such as $\mathrm{pH}$, alkalinity and NOM, the actual concentration of cyanotoxins and other pollutants dictates the $\mathrm{O}_{3}$ demand of water. However, the effects of water quality on the pollutant removal are neglectable once a residual $\mathrm{O}_{3}$ concentration is present in the treated water. Hence, an ozone residual of $>0.3 \mathrm{mg} \mathrm{L}^{-1}$ for $\geq 5 \mathrm{~min}$, which is typically applied in water treatment plants, is recommended for cyanotoxin removal [2].

\section{Photolysis}

Photolysis occurs in the environment by exposure to sunlight and is commonly employed for disinfection in water treatment utilizing UV light. Upon absorption of light, energy is released from a molecule through physical and chemical processes which include the breakdown of a compound [50]. Although ANTX readily degrades under sunlight in absence of photosensitizers $\left(t_{1 / 2}=1-2 \mathrm{~h}\right.$ at alkaline $\mathrm{pH}$ ) [51], other cyanotoxins such as MCs and CYN are less susceptible to direct photodegradation by sunlight [52]. Efficacy of photolytic treatment strongly depends on the wavelength, i.e., energy of the used light. For instance, ANTX has an absorption maximum in the range of $230-240 \mathrm{~nm}$, which determines the toxin's resistance to UV-A irradiation (315-400 nm), while it degrades by $70 \%$ under UV-C irradiation at $254 \mathrm{~nm}$ [39]. Similarly, NOD degradation also improved when UV light of a shorter wavelength, i.e., higher energy, was used [53]. With vacuum-UV at $172 \mathrm{~nm}$, water is directly photolyzed to form .OH (Eq. 9), which further increased ANTX degradation and substantially reduced the UV dose required for complete removal. However, direct water photolysis is strongly limited to a light penetration depth in water of $<100 \mu \mathrm{m}$, which makes $\mathrm{OH}$ formation by vacuum-UV less attractive to drinking water treatment compared to other AOPs [54].

$$
\mathrm{H}_{2} \mathrm{O}+\mathrm{hv}(172 \mathrm{~nm}) \rightarrow \mathrm{H}_{2} \mathrm{O}^{*} \rightarrow \mathrm{H} \cdot+\cdot \mathrm{OH}
$$

Besides wavelength, light intensity is a crucial parameter as well. MC-LR degradation increased by about $30-40 \%$ when light intensity was tripled [55]. Moreover, at $254 \mathrm{~nm}$ and a dose of $564 \mathrm{~mJ} \mathrm{~cm} \mathrm{~cm}^{-2}$, approximately 66\% MC-LR degradation was achieved, while at $312 \mathrm{~nm}$, a much higher dose of $11,304 \mathrm{~mJ} \mathrm{~cm}^{-2}$ was required to yield similar results $[55,56]$. In addition to irradiation, degradation also depends on the toxin structure as shown in a study on UV-photolytic treatment of four MCs, where degradation increased from $M C-L R<-R R<-Y R<-L A$ owing to the different amino acid structures $(\mathrm{A}=$ alanine, $\mathrm{L}=$ leucine, $\mathrm{R}=$ arginine, $\mathrm{Y}=$ tyrosine) [41].

UV-based treatments are so far the only methods for which MC-LR detoxification due isomerization of the 4(E),6(E)-Adda chain (Fig. 1) to 4(Z)- or 6(Z)-Adda was observed. Furthermore, degradation mechanisms include decarboxylation, which has only been reported for UVbased methods and sulfate radical-based AOPs (SRAOPs; see the section on "Sulfate radical-based AOPs") $[56,57]$.

Cyanotoxins usually co-occur with NOM which can act as photosensitizer and improve the degradation. For instance, MC-RR photodegradation by sunlight substantially increased in presence of the cyanobacterial pigment phycocyanin [58]. However, photosensitizer concentration is essential as it was shown for MC-LR degradation. At lower concentrations, pigment availability was the limiting factor, while at higher concentrations, light attenuation was significant [59]. In a similar manner, ANTX photodegradation was more effective in the presence of NOM but the degradation decreased with increasing NOM concentration. Experiments with quenchers showed that besides excited $\mathrm{NOM},{ }^{1} \mathrm{O}_{2}$ and $\cdot \mathrm{OH}$ also contributed to the toxin degradation and that ${ }^{1} \mathrm{O}_{2}$ was more important than $\cdot \mathrm{OH}$ [60]. In contrast, photosensitized CYN degradation was observed to be mainly driven by $\cdot \mathrm{OH}$ (about 
65-70\%), with ${ }^{1} \mathrm{O}_{2}$ and excited NOM only playing minor roles [61]. This disagreement may not only be related to the different toxins, but also to experimental conditions and using fulvic acid and solar light vs humic acid and UV-C light, respectively. Although phycocyanin did not improve CYN photodegradation, other cyanobacterial compounds were observed to accelerate NOD and CYN degradation $[53,62,63]$. In fact, the presence of different pigment types was shown to affect MC-LR photodegradation effectivity in the following order: without pigment $<$ chlorophyll $\mathrm{a}<\beta$-carotene $<$ water-extractable pigments $<$ solvent-extractable pigments [58]. Furthermore, higher light intensities led to pigment bleaching and degradation which adversely affected MC-LR degradation [59].

Turbidity is one of the most important water quality parameters for photodegradation. Light absorption by non-target water constituents not acting as photosensitizer attenuates light and reduces penetration depth. Therefore, photodegradation is usually efficient in relatively clear water, after most turbidity has been removed [10]. Other water quality parameters may also affect the degradation as shown for ANTX degradation by UV-C radiation, where toxin removal was more effective at acidic $\mathrm{pH}$ with an optimum at $\mathrm{pH}=6.4$, most likely due to ANTX speciation under acidic conditions $\left(\mathrm{pK}_{\mathrm{a}}=9.4\right)$ and possible inter- and intramolecular hydrogen bonding under alkaline $\mathrm{pH}$. Also, higher temperatures led to increased ANTX degradation, but the changes became insignificant at $T>24{ }^{\circ} \mathrm{C}$. Last, as for most AOPs, alkalinity was observed to decrease ANTX degradation due to quenching of reactive species [60].

To achieve high degradation yields, UV doses substantially higher than those commonly used for disinfection in water treatment $\left(10-40 \mathrm{~mJ} \mathrm{~cm}{ }^{-2}\right.$ [9]) are required. Consequently, to reduce energy demand and operating costs for large-scale water treatment, the combination of UV with oxidants or photocatalysts-as discussed in the following paragraphs-is inevitable.

\section{Photolysis in combination with oxidants}

The combination of UV radiation with $\mathrm{H}_{2} \mathrm{O}_{2}$ or $\mathrm{O}_{3}$ improves pollutant degradation due to the photolytic production of .OH (Eqs. 10 and 11) [56]. Moreover, $\cdot \mathrm{OH}$ and $\mathrm{SO}_{4}^{-}$. are produced from peroxymonosulfate (PMS) or peroxydisulfate (also persulfate, PS) upon UV activation (see the section on "Sulfate radical-based AOPs"). In a UV/ chlorine system, $\cdot \mathrm{OH}, \mathrm{Cl} \cdot \mathrm{OCl} \cdot$ and other reactive species are formed following Eqs. (12) to (16) [64].

$$
\begin{aligned}
& \mathrm{O}_{3}+\mathrm{H}_{2} \mathrm{O}+\mathrm{hv} \rightarrow \mathrm{O}_{2}+\mathrm{H}_{2} \mathrm{O}_{2} \\
& \mathrm{H}_{2} \mathrm{O}_{2}+\mathrm{hv} \rightarrow 2 \cdot \mathrm{OH}
\end{aligned}
$$

$$
\begin{aligned}
& \mathrm{HOCl}+\mathrm{hv} \rightarrow \cdot \mathrm{OH}+\mathrm{Cl} . \\
& \mathrm{OCl}^{-}+\mathrm{hv} \rightarrow \mathrm{O}^{-} \cdot+\mathrm{Cl} . \\
& \mathrm{Cl} \cdot+\mathrm{Cl}^{-} \rightarrow \mathrm{Cl}_{2}^{-} \cdot \\
& \mathrm{HOCl} / \mathrm{OCl}^{-}+\cdot \mathrm{OH} \rightarrow \mathrm{H}_{2} \mathrm{O} / \mathrm{OH}^{-}+\mathrm{OCl} \cdot \\
& \mathrm{HOCl} / \mathrm{OCl}^{-}+\mathrm{Cl} \cdot \rightarrow \mathrm{HCl} / \mathrm{Cl}^{-}+\mathrm{OCl} \cdot \\
& \cdot \mathrm{OH}+\mathrm{H}_{2} \mathrm{O}_{2} \rightarrow \cdot \mathrm{HO}_{2}+\mathrm{H}_{2} \mathrm{O}
\end{aligned}
$$

UV in combination with oxidants has been studied for the removal of MCs, CYN, ANTX and BMAA. For all for toxins, UV-based treatment was substantially more effective when $\mathrm{H}_{2} \mathrm{O}_{2}$ was added [37, 39, 40, 54, 55, 60]. Increasing $\mathrm{H}_{2} \mathrm{O}_{2}$ concentration improved cyanotoxin degradation only up to a certain oxidant concentration. Once the optimal $\mathrm{H}_{2} \mathrm{O}_{2}$ level was exceeded, .OH quenching by $\mathrm{H}_{2} \mathrm{O}_{2}$ (Eq. 17) outbalanced radical formation [54, 55, 60]. Different studies reported that MCs were degraded at higher rates compared to CYN, ANTX and BMAA because of their higher reactivity with $\cdot \mathrm{OH}$. This is caused by MCs' size and higher number of functional moieties that are partly more susceptible to radical attack [37, 41, 65]. The importance of the structure for the reactivity with $\cdot \mathrm{OH}$ is further affirmed when looking at different MCs. The major part of their structures is similar with the main difference being two amino acids (see Fig. 1). However, these minor differences suffice to yield different degradation rate constants: MC-YR $\left(1.63 \times 10^{10} \mathrm{M}^{-1} \mathrm{~s}^{-1}\right)>\mathrm{MC}-\mathrm{RR}$ $\left(1.45 \times 10^{10} \mathrm{M}^{-1} \mathrm{~s}^{-1}\right)>$ MC-LR $\left(1.13 \times 10^{10} \mathrm{M}^{-1} \mathrm{~s}^{-1}\right)>$ MC-LA $\left(1.10 \times 10^{10} \mathrm{M}^{-1} \mathrm{~s}^{-1}\right)$ [41].

When $\mathrm{O}_{3}$ was added to UV instead of $\mathrm{H}_{2} \mathrm{O}_{2}$, MC-LR degradation also became more effective compared to $\mathrm{UV}$ - and $\mathrm{O}_{3}$-only treatment. $\mathrm{O}_{3}$ decomposition to $\cdot \mathrm{OH}$ is accelerated under UV irradiation and as a consequence, both $\mathrm{O}_{3}$ and $\cdot \mathrm{OH}$ oxidize pollutants [56, 66]. Although $\mathrm{O}_{3}$, i.e., its production, may be more expensive compared to $\mathrm{H}_{2} \mathrm{O}_{2}$ and $\mathrm{TiO}_{2}$ (for $\mathrm{UV} / \mathrm{TiO}_{2}$ see the section on "Photocatalysis"), to achieve similar results, shorter reaction times and lower oxidant doses were required compared to $\mathrm{UV} / \mathrm{H}_{2} \mathrm{O}_{2}$ treatment [56]. Due to the UV irradiation, decarboxylation and isomerization of MC-LR were observed, which did not occur in $\mathrm{O}_{3}$-only treatment. Furthermore, compared to UV- and $\mathrm{O}_{3}$-only treatment, UV/ $\mathrm{O}_{3}$ had a higher potential to degrade MC-LR and its degradation intermediates simultaneously under the same conditions [56].

As another, cheaper alternative to $\mathrm{H}_{2} \mathrm{O}_{2}$, the addition of chlorine has been studied in UV-based AOPs [67]. 
$\mathrm{UV} /$ chlorine was shown to be more effective compared to $\mathrm{UV} / \mathrm{H}_{2} \mathrm{O}_{2}$, UV- and chlorine-only MC-LR treatment. Besides producing a variety of reactive oxygen and chlorine species (Eqs. 12 to 16), $\mathrm{Cl}$. is more selective than $\cdot \mathrm{OH}$ and preferably reacts with electron-rich moieties [64]. Similar to $\mathrm{UV} / \mathrm{H}_{2} \mathrm{O}_{2}$, increasing the chlorine dose led to a more effective MC-LR degradation due to an increase in reactive chlorine species production and higher contribution to toxin degradation [64, 67]. However, the use of chlorine may lead to the formation of halogenated degradation products such as chloroform and dichloroacetic acid produced from MC-LR following a series of oxidation steps [67]. Even though yields of these chlorinated byproducts increased with prolonged treatment time, residual cytotoxicity after $\mathrm{UV} /$ chlorine treatment was lower compared to untreated MC-LR [67].

Besides oxidant type and dose, the UV radiation itself is an important factor, as the peroxide bond in $\mathrm{H}_{2} \mathrm{O}_{2}$ is cleaved only upon irradiation with light of $\lambda<300 \mathrm{~nm}$ [39]. Hence, MC-LR and ANTX degradation by UV-A/ $\mathrm{H}_{2} \mathrm{O}_{2}\left(\lambda_{\text {UV-A }} \approx 400-315 \mathrm{~nm}\right)$ has been reported to be substantially less effective compared to UV- $\mathrm{B} / \mathrm{H}_{2} \mathrm{O}_{2}$ and $\mathrm{UV}-\mathrm{C} / \mathrm{H}_{2} \mathrm{O}_{2}\left(\lambda_{\mathrm{UV}-\mathrm{B}} \approx 315-280 \mathrm{~nm}, \lambda_{\mathrm{UV}-\mathrm{C}} \approx 280-100 \mathrm{~nm}\right)$, respectively $[39,55,68]$.

Similar to other AOPs, water quality parameters can influence UV/oxidant degradation efficacy. In the UV/ oxidant setup NOM rather acts as oxidant and radical quencher than as photosensitizer, thus decreasing removal efficacy, which is in contrast with NOM action during photolysis without the addition of oxidants. NOM may compete with the oxidant for UV photons which consequently reduce reactive species formation $[60,65$, 69]. The $\mathrm{UV} / \mathrm{O}_{3}$ system was also affected by NOM but to lesser extent than $\mathrm{O}_{3}$-only treatment of MC-LR [56]. In case of UV/chlorine degradation of MC-LR, NOM did not only decrease the degradation, but also resulted in a higher yield of chlorinated byproducts. This yield was observed to be dependent on NOM as well as chlorine dosage [67]. In the presence of bromide, MC-LR degradation increased due to the formation of $\mathrm{HOBr}$ which is more reactive than $\mathrm{HOCl}$ toward phenolic and amine moieties. Furthermore, UV activation of $\mathrm{HOBr}$ formed reactive bromine species which may have contributed to MC-LR degradation [64]. Alkalinity decreased $\mathrm{UV} / \mathrm{H}_{2} \mathrm{O}_{2}$ and $\mathrm{UV} /$ chlorine degradation efficacy similar to NOM due to $\mathrm{H}_{2} \mathrm{O}_{2}$ and radical quenching $[64,69]$.

UV/oxidant removal efficacy is also affected by water $\mathrm{pH}$. For ANTX removal by $\mathrm{UV} / \mathrm{H}_{2} \mathrm{O}_{2}$, the highest efficacy was achieved at $\mathrm{pH} 6.7$, while at lower $\mathrm{pH}$ the $\cdot \mathrm{OH}$ yield decreased due to reactions with $\mathrm{H}^{+}$and at alkaline pH ANTX is deprotonated and exists as neutral amine $\left(\mathrm{pK}_{\mathrm{a}}=9.4\right)$. In this form, inter- and intramolecular hydrogen bonds can form which affect ANTX reactivity with
.OH [39]. In contrast, for BMAA removal, alkaline $\mathrm{pH}$ appeared to increase the degradation rate constant due to BMAA speciation at higher $\mathrm{pH}$ [37]. In $\mathrm{UV} / \mathrm{O}_{3}$ systems, the $\mathrm{pH}$ does not only determine toxin speciation, but also $\mathrm{O}_{3}$ stability, which decreases at alkaline $\mathrm{pH}$ and may affect toxin degradation. However, this effect seemed to be less influential for MC-LR degradation by $\mathrm{UV} / \mathrm{O}_{3}$ compared to $\mathrm{O}_{3}$-only treatment [56]. In UV/chlorine-based treatment, the oxidant itself is also strongly affected by the $\mathrm{pH}$, when $\mathrm{HOCl}$ dissociates to $\mathrm{OCl}^{-}$at alkaline $\mathrm{pH}\left(\mathrm{pK}_{\mathrm{a}}=7.5\right) . \mathrm{OCl}^{-}$has a lower molar absorption and thus a lower radical yield. Furthermore, $\mathrm{OCl}^{-}$ reacts at a higher rate with $\cdot \mathrm{OH}$ and $\mathrm{Cl}$. compared to $\mathrm{HOCl}$. The optimum $\mathrm{pH}$ for MC-LR degradation by UV/ chlorine was determined to be $\mathrm{pH}$ 7.4 [67]. In contrast, in another study MC-LR degradation by UV/chlorine was shown to be most effective at $\mathrm{pH} 6$ and decreased at $\mathrm{pH}$ 7 [64]. Most of the experimental conditions seemed to be very similar, i.e., oxidant type and concentration, UV wavelength, MC-LR concentration and $\mathrm{pH}$-buffer composition but notable differences were the UV intensity and $\mathrm{pH}$-buffer concentration, which could have affected the outcomes. Both studies also examined the contribution of different reactive species to MC-LR degradation and reported different findings. In the first study, at neutral $\mathrm{pH}, \mathrm{MC}-\mathrm{LR}$ degradation by UV/chlorine was dominated by $\cdot \mathrm{OH}(42.5 \%)$, while $\mathrm{Cl}_{2}(25.4 \%)$, $\mathrm{ClO} \cdot(13.3 \%)$, Cl. (11.1\%) and UV (8.5\%) contributions were lower [67]. In the second study, at neutral $\mathrm{pH}, \mathrm{MC}-\mathrm{LR}$ degradation was driven by $\mathrm{HOCl} / \mathrm{OCl}^{-}(47.3 \%)$, while reactive chlorine species (21.3\%), UV (21.1\%) and $\cdot \mathrm{OH}(10.3 \%)$ were only partially responsible for MC-LR degradation. Also in the second study, the UV intensity was about twice as high compared to the first study, which may explain the difference in the higher UV contribution [64].

\section{Photocatalysis}

Instead of oxidants, photoactive semiconductors can be used to improve UV-based cyanotoxin degradation. Upon exposure to light with energy exceeding the band gap between occupied valence band and unoccupied conductance band, an electron migrates from the valence to the conductance band. The formed valence band hole yields an oxidative site, while the now occupied conductance band provides a reducing site. As a result, three reaction mechanisms are possible: (i) direct oxidation at the valence band, (ii) $\cdot \mathrm{OH}$ formation from $\mathrm{H}_{2} \mathrm{O}$ or $\mathrm{OH}^{-}$at the valence band, and (iii) $\mathrm{O}_{2}^{-}$. and subsequent $\mathrm{H}_{2} \mathrm{O}_{2}$ formation from $\mathrm{O}_{2}$ at the conductance band [70].

Photocatalysis was shown to be effective for the removal of MCs, NOD and CYN [71-74]. Besides toxin degradation, adsorption onto the catalyst is often reported as a fourth removal mechanism. In a study with 
different MCs, degradation was faster, when adsorption to the catalyst was the highest [75], while in another study, no correlation of MC and NOD degradation with dark adsorption was observed [74]. In the first study, $\mathrm{TiO}_{2}$ powder was used as received [75], while in the second study, the catalyst was coated onto glass spheres [74], which may have caused these contradicting findings. Effectivity of dark adsorption depends on toxin composition and hydrophobicity in particular. Adsorption to $\mathrm{TiO}_{2}$ increased with increasing pollutant hydrophobicity and was thus $\mathrm{pH}$-dependent, caused by compound speciation and change of hydrophobicity at certain $\mathrm{pH}$. Hence, for MCs, adsorption increases at acidic $\mathrm{pH}[75,76]$.

Because of its high oxidizing power, chemical stability and low cost, $\mathrm{TiO}_{2}$ is a commonly used photocatalyst [70]. Toxin degradation is accelerated with increasing $\mathrm{TiO}_{2}$ concentration, but levelled off once a certain catalyst concentration was reached [72-74]. However, $\mathrm{TiO}_{2}$ is only photoactive at UV light, which limits its applicability. Therefore, $\mathrm{TiO}_{2}$ has been doped with mostly non-metal elements to reduce the band gap and consequently decrease the energy required for its activation [77]. Although $\mathrm{N}$-doped $\mathrm{TiO}_{2}$ was less effective than pure $\mathrm{TiO}_{2}$ under UV and solar light, MC-LR could only be removed under visible light with $\mathrm{N}-\mathrm{TiO}_{2}$ [73]. Further, N-F-co-doped $\mathrm{TiO}_{2}$ achieved higher removal compared to $\mathrm{N}$ - or $\mathrm{F}-\mathrm{TiO}_{2}$ under visible light [77]. For the removal of 6-hydromethyl uracil, a CYN model compound, under UV light, degradation efficacy for different co-doped $\mathrm{TiO}_{2}$ was in order: N-F-TiO $>$ P-F$\mathrm{TiO}_{2}>\mathrm{S}-\mathrm{TiO}_{2}$, while $\mathrm{N}-\mathrm{F}-\mathrm{TiO}_{2}$ was the only catalyst which removed the uracil derivative under visible light [78]. MC-LR could be removed by $\mathrm{Vis} / \mathrm{S}-\mathrm{TiO}_{2}$ due to the different toxin structure, allowing MC-LR adsorption to the photocatalyst and consequently allowing for degradation [79]. Similarly, C-doped $\mathrm{TiO}_{2}$ showed lower removal rates under UV light compared to pure $\mathrm{TiO}_{2}$, but in contrast, achieved MC-LR and CYN degradation under visible light. Differences in the reaction products and reactive species involved revealed distinct reaction mechanisms under UV and visible light [71]. Under UV light, $\cdot \mathrm{OH}$ was the primary reactive species, while under visible light, $\mathrm{O}_{2}^{-}$. became more important $[71,78,80]$. Besides doped $\mathrm{TiO}_{2}$, other photocatalysts, e.g., $\mathrm{WO}_{3}$ and $\mathrm{Fe}_{2} \mathrm{O}_{3}$ showed high response to solar light and were used for MC-LR degradation [81, 82]. Similar to $\mathrm{TiO}_{2}$, doping of $\mathrm{WO}_{3}$ improved MC-LR degradation and dopants can be ordered according to the removal rate: $\mathrm{WO}_{3}<\mathrm{CuO}-$ $\mathrm{WO}_{3}<\mathrm{Pd}-\mathrm{WO}_{3} \ll \mathrm{Pt}-\mathrm{WO}_{3}$ [81]. When $\mathrm{BiOBr}$ was used as photocatalyst, MC-LR and CYN degradation was achieved by direct reaction with the catalyst instead of radicals, which followed a different reaction mechanism, involving decarboxylation [83, 84].
A major limitation of photocatalysis is the need to remove the catalyst in a subsequent treatment step, which becomes even more difficult if nano-scale powder is used. Hence, employing heterogeneous or immobilized photocatalysts improves or avoids removal and makes photocatalysis more attractive for large-scale water treatment. Besides substrates like glass or PVC, cellulose acetate and PET monoliths were found to be the best supporting materials for $\mathrm{TiO}_{2}$ photocatalytic treatment of MC-LR and CYN [85]. When coated onto granular-activated carbon, $\mathrm{TiO}_{2}$ photocatalysis of MC-LR improved compared to pure $\mathrm{TiO}_{2}$ powder due to increased adsorption to $\mathrm{TiO}_{2}$ or to activated carbon sites in vicinity to the catalyst [86]. In case of Fe-based photocatalysts, immobilization to a substrate is evitable because they can be separated magnetically [82].

Similar to photolysis, photocatalysis efficacy depends on the light characteristics, i.e., wavelength and intensity in particular. Although doped $\mathrm{TiO}_{2}$ is also activated under visible light, degradation rates are reduced by two to three orders of magnitude compared to UV or solar light $[71,73]$. With higher light intensities, more electron-hole pairs are formed regardless of the employed photocatalyst, which results in higher toxin removal [72, 81].

When $\mathrm{UV} / \mathrm{TiO}_{2}$ was combined with $\mathrm{H}_{2} \mathrm{O}_{2}$, higher MC-LR degradation was achieved compared to UV/ $\mathrm{TiO}_{2}$ or $\mathrm{UV} / \mathrm{H}_{2} \mathrm{O}_{2}$ alone [87]. Although dark adsorption to the catalyst decreased in the presence of the oxidant, $\mathrm{H}_{2} \mathrm{O}_{2}$ decomposition to $\cdot \mathrm{OH}$ increased when $\mathrm{TiO}_{2}$ was present. However, $\mathrm{H}_{2} \mathrm{O}_{2}$ concentration was shown to be a crucial factor, as the MC-LR degradation rate was highest at $0.005 \% \mathrm{H}_{2} \mathrm{O}_{2}$ in solution and decreased at higher concentrations [87]. Besides adding oxidants, photocatalysis can also be enhanced when used in photoelectrocatalysis. Similar to elemental doping of a photocatalyst, photoelectrocatalysis improves the photocatalytic activity by removing electrons from the catalyst to reduce the recombination of electron-hole pairs to instead utilize the holes in the conductance band for oxidant production and pollutant reduction [88]. Under given experimental conditions, MC-LR degradation was substantially more effective by photoelectrocatalysis using $\mathrm{Ag} / \mathrm{AgCl} /$ $\mathrm{TiO}_{2}$ nanotube electrodes compared to photocatalysis and electrochemical degradation alone [89]. Because this approach is based on an electrolytic cell, parameters such as electrolyte composition affect the degradation and need to be optimized (see the section on "Electrochemical oxidation").

Also for photocatalytic toxin removal, water quality parameters such as $\mathrm{pH}$ and NOM have major an impact. For instance, regardless of type and doping of the photocatalyst, higher $\mathrm{MC}$ and $\mathrm{CYN}$ removal was achieved 
under acidic conditions [72, 76, 82]. However, when different scavengers were used during MC-LR degradation by $\mathrm{Vis} / \mathrm{NF}-\mathrm{TiO}_{2}$, the solution $\mathrm{pH}$ did not only affect dark adsorption, but also played a crucial role in the formation and reactivity of reactive oxygen species [80]. Although NOM can act as photosensitizer in photolysis, it may adsorb to the catalyst surface and quench reactive species produced by photocatalysis which reduces toxin removal. Similarly, high alkalinity quenches and thus limits $\cdot \mathrm{OH}$ availability [76]. Another crucial water quality parameter is dissolved $\mathrm{O}_{2}$ which functions as precursor for $\mathrm{O}_{2}{ }^{-}$. and $\mathrm{H}_{2} \mathrm{O}_{2}$ formation at the conductance band. Under $\mathrm{O}_{2}$-free atmosphere, cyanotoxin degradation substantially decreased or was completely inhibited [72, 78]. In the presence of $\mathrm{Fe}^{3+}$ and $\mathrm{Cu}^{2+}$, toxin degradation increased due to $\mathrm{OH}$ production in a Fenton-like reaction $[78,81]$ (see the section on "Fenton oxidation"). At lower concentrations, $\mathrm{Cl}^{-}$can function as a precursor for $\mathrm{Cl}$. which was shown to increase MC-LR degradation. However, when exceeding an optimal $\mathrm{Cl}^{-}$concentration, . OH quenching and $\mathrm{Cl}_{2}$ formation became more efficient and suppressed toxin degradation [81].

\section{Fenton oxidation}

In a Fenton reaction $\mathrm{OH}$ is produced via the reaction shown in Eq. (18). The Fenton's reagent thereby refers to $\mathrm{Fe}^{2+} / \mathrm{H}_{2} \mathrm{O}_{2}$, but other transition metals, e.g., chromium, copper, manganese as well as other oxidants, e.g., $\mathrm{HClO}, \mathrm{S}_{2} \mathrm{O}_{8}{ }^{2-}$ or $\mathrm{HSO}_{5}{ }^{-}$can also produce $\cdot \mathrm{OH}$ or $\mathrm{SO}_{4}{ }^{-}$. in Fenton-like reactions (see the section on "Sulfate radical-based AOPs" for $\mathrm{SO}_{4}^{-}$- production") [36, 90]. Fenton oxidation of several cyanotoxins was studied, and the removal effectiveness was found to be in order of MC- $R$ $\mathrm{R}>\mathrm{CYN}>\mathrm{MC}-\mathrm{LR} \gg \mathrm{ANTX}>\mathrm{STX}[36,38,44,45,91,92]$.

$$
\begin{aligned}
& \mathrm{Fe}^{2+}+\mathrm{H}_{2} \mathrm{O}_{2} \rightarrow \mathrm{Fe}^{3+}+\cdot \mathrm{OH}+\mathrm{OH}^{-} \\
& \mathrm{Fe}^{3+}+\mathrm{H}_{2} \mathrm{O}_{2} \rightarrow \mathrm{Fe}^{2+}+\mathrm{HO}_{2} \cdot+\mathrm{H}^{+} \\
& \mathrm{Fe}^{3+}+\mathrm{HO}_{2} \cdot \rightarrow \mathrm{Fe}^{2+}+\mathrm{O}_{2}+\mathrm{H}^{+} \\
& \mathrm{Fe}^{2+}+\cdot \mathrm{OH} \rightarrow \mathrm{Fe}^{3+}+\mathrm{OH}^{-}
\end{aligned}
$$

The $\mathrm{Fe}^{2+}$ to $\mathrm{H}_{2} \mathrm{O}_{2}$ ratio is among the most crucial parameter that must be optimized to prevent parasitic reactions which inhibit $\cdot \mathrm{OH}$ formation. In case of $\mathrm{H}_{2} \mathrm{O}_{2}$ excess, $\mathrm{Fe}^{3+}$ is reduced to $\mathrm{Fe}^{2+}$ at a slower rate as the Fenton reaction, consuming $\mathrm{H}_{2} \mathrm{O}_{2}$ to yield $\mathrm{HO}_{2}$. (Eqs. 19 and 20). The formation of the less reactive $\mathrm{HO}_{2}$. is competing with the formation of more reactive $\mathrm{OH}$ (Table 1 ). An excess in $\mathrm{H}_{2} \mathrm{O}_{2}$ also leads to the formation of $\mathrm{HO}_{2}$. by $\cdot \mathrm{OH}$ depletion (Eq. 17). In addition, $\cdot \mathrm{OH}$ can be quenched by an excess of $\mathrm{Fe}^{2+}$ (Eq. 21) [90]. Several studies reported different optimal $\mathrm{Fe}^{2+}$ to $\mathrm{H}_{2} \mathrm{O}_{2}$ ratios, even for the same toxins, which emphasizes that experimental conditions like toxin concentration and solution $\mathrm{pH}$ must be considered [38, 44, 45, 93].

Fenton oxidation is often reported to be most effective at $\mathrm{pH} \approx 3$ [90]. At alkaline $\mathrm{pH}, \mathrm{Fe}^{2+}$ forms hydroxides which tend to precipitate, thus reducing $\mathrm{Fe}^{2+}$ availability to produce $\cdot \mathrm{OH}$ [38]. Furthermore, $\mathrm{H}_{2} \mathrm{O}_{2}$ stability decreases at alkaline $\mathrm{pH}$ which further limits $\cdot \mathrm{OH}$ formation [94]. On the other hand, under too strong acidic conditions, $\mathrm{H}^{+}$inhibits $\mathrm{Fe}^{3+}$ reduction which also decreases $\mathrm{Fe}^{2+}$ availability [93]. For practical applications, treatment closer to neutral $\mathrm{pH}$ may be beneficial as it would reduce resources and costs required for $\mathrm{pH}$ adjustments before and after Fenton treatment while keeping a sufficient effectiveness, e.g., $77 \%$ MC-LR removal at $\mathrm{pH} 3$ and $68 \%$ removal at $\mathrm{pH} 5,[38]$. To extend the $\mathrm{pH}$ range, heterogeneous or immobilized catalysts can be used which additionally improves its removability from water. For instance, across a $\mathrm{pH}$ range of 5-8 in a photoFenton process, heterogeneous FeY was shown to yield a higher catalytic activity than $\mathrm{Fe}^{2+}$ [95]. Although alkaline $\mathrm{pH}$ is often reported to decrease Fenton effectiveness due to lower $\cdot \mathrm{OH}$ yields, the formation of alternative oxidants at neutral and alkaline $\mathrm{pH}$ was proposed in a study with Reactive Black 5 and $\mathrm{As}^{3+}$ [96]. Oxidation increased again under alkaline $\mathrm{pH}$ which was associated with highvalent iron species, i.e., $\mathrm{Fe}^{4+}$, in form of hydroxo-complexes [96].

In Fenton-like reactions, transition metals and oxidants other than $\mathrm{Fe}^{2+}$ and $\mathrm{H}_{2} \mathrm{O}_{2}$ produce $\cdot \mathrm{OH}$. For instance, $\mathrm{Fe}^{3+}$ can be used instead of $\mathrm{Fe}^{2+}$. However, MC-LR degradation was shown to be significantly slower, because $\mathrm{Fe}^{3+}$ first is reduced to $\mathrm{Fe}^{2+}$ by $\mathrm{H}_{2} \mathrm{O}_{2}$ (Eqs. 19 and 20) before it eventually produces $\cdot \mathrm{OH}$ [97]. Besides MC-LR, CYN and ANTX were also shown to be degraded by a Fenton-like system, namely $\mathrm{Fe}^{3+}$, which was bond to a macrocyclic ligand system, in combination with $\mathrm{H}_{2} \mathrm{O}_{2}$ [91]. In another study, $\mathrm{Cu}^{2+}$ in combination with ascorbic acid was used to degrade MC-LR. Ascorbic acid reduced $\mathrm{Cu}^{2+}$ to $\mathrm{Cu}^{+}$which then activated $\mathrm{O}_{2}$ to form $\mathrm{H}_{2} \mathrm{O}_{2}$ via $\mathrm{O}_{2}{ }^{-} \cdot \mathrm{Cu}^{+} / \mathrm{H}_{2} \mathrm{O}_{2}$ produced $\cdot \mathrm{OH}$ at a rate of approximately $100 \mathrm{M}^{-1} \mathrm{~s}^{-1}$ which is in a similar range as the $\mathrm{Fe}^{2+} / \mathrm{H}_{2} \mathrm{O}_{2}$ system $\left(76 \mathrm{M}^{-1} \mathrm{~s}^{-1}\right)$ [98].

Fenton oxidation can be improved when combined with UV/Vis light which leads to photoreduction of $\mathrm{Fe}^{3+}$ to $\mathrm{Fe}^{2+}$ as well as photolytic $\cdot \mathrm{OH}$ generation from $\mathrm{H}_{2} \mathrm{O}_{2}$ [68]. Photo-Fenton was shown to be more effective compared to dark Fenton MC-LR degradation due to combined effects of photolytic and Fenton mechanisms [99]. Due to the continuous photoreduction of $\mathrm{Fe}^{3+}$ and photocatalytic $\cdot \mathrm{OH}$ generation from $\mathrm{Fe}^{3+}$ in form of $\mathrm{Fe}(\mathrm{OH})^{2+}$, $\mathrm{UV}-\mathrm{C} / \mathrm{Fe}^{3+} / \mathrm{H}_{2} \mathrm{O}_{2}$ was more effective than $\mathrm{UV}-\mathrm{C} / \mathrm{Fe}^{2+}$ / 
$\mathrm{H}_{2} \mathrm{O}_{2}$ for the degradation of MC-LR [68]. Furthermore, the spectrum of the irradiation light was also shown to affect MC-LR degradation, as UV-C and solar light were more effective than UV-A $[68,100]$. Other hybrid Fenton techniques use ultrasound or electrolysis (for electroFenton see the section on "Electrochemical oxidation") to improve pollutant removal. In sono-Fenton, $\cdot \mathrm{OH}$ formation is further accelerated by combining sonochemical (see the section on "Sonolysis") and Fenton mechanisms [101].

As for most AOPs, NOM quenches produced $\cdot \mathrm{OH}$ and may thus reduce the effectiveness of Fenton oxidation [38]. Although CYN degradation by Fenton oxidation decreased in the presence of NOM, the effect appeared to be less extensive compared to, e.g., ozonation and UV/ $\mathrm{TiO}_{2}$ [92]. Photo-Fenton may be more affected by NOM due to light attenuation [68]. However, the effect of NOM on the degradation strongly depends on its type and composition. The removal rate of MC-LR by solar photo-Fenton in presence of different NOM types was in the order of fulvic acid $>$ NOM-free $>$ humic acid $>$ a mixture of fulvic and humic acids plus bicarbonate as alkalinity. Humic acid usually has a larger molecular weight and contains more aromatic moieties than fulvic acid which, in turn, may act as a chelating agent, stabilizing $\mathrm{Fe}^{2+}[102]$. Similarly, when zero-valent iron nanoparticles were used in a heterogeneous Fenton-like reaction, humic acid seemed to form $\mathrm{H}_{2} \mathrm{O}_{2}$-cleaving iron complexes which resulted in higher MC-LR degradation [103].

\section{Non-thermal plasma}

Low or atmospheric pressure plasmas in which most of the energy is transmitted to free electrons (temperatures of $\geq 10^{4} \mathrm{~K}$ ), while the remaining heavy species only receive minor amounts of energy (temperatures of $\leq 10^{3} \mathrm{~K}$ ), are called non-thermal plasmas (NTPs). A broad spectrum of reactive species is generated by NTPs, including hot electrons, photons, and heavy species such as radicals, excited atoms, molecules and ions, reactive oxygen and nitrogen species. In addition, some discharges may generate shock waves [104, 105]. NTPs are generated by electric discharges in the gaseous or liquid phase, or at their interface and due to the overall low plasma temperature can be employed in many different fields including water treatment $[104,106]$. In fact, because of higher efficiencies compared to other means of $\mathrm{O}_{3}$ production, $\mathrm{O}_{3}$ generators are often based on electric discharges in air or oxygen [106].

For an electric discharge in gas, the gas type and composition dictate which reactive species are produced. For a discharge in air or oxygen, one of the most important processes is $\mathrm{O}_{3}$ formation. However, in the presence of $\mathrm{N}_{2}$, i.e., in discharges in air, $\mathrm{NO}_{\mathrm{x}}$ are also produced, which lead to acidification and nitrification of the solution if the gas is bubbled through water afterward [107]. $\mathrm{O}_{3}$ produced in gas can directly react with pollutants or dissolve into the liquid when the gas is bubbled through the solution after the discharge, where it can also decompose to $\cdot \mathrm{OH}$ [108]. If oxygenfree gases such as Ar are used, no reactive oxygen species are produced in the gas phase, but when the gas passes through water, $\mathrm{OH}$ can be formed upon reaction with ionized or excited species in the gas [109]. In electric discharges in water, low-energy electrons excite water molecules, whereas high-energy electrons dissociate water. Both reactions lead to the formation of .OH (Eqs. 22 and 23), which is one of the main reactive species produced by a discharge in water. $\mathrm{H}_{2} \mathrm{O}_{2}$ is formed as a recombination product of $\cdot \mathrm{OH}$ [107]. With a discharge in liquid, reactive species can directly react with pollutants in the plasma channels or close to the plasma-liquid boundary without the need to diffuse from the gaseous into the liquid phase [110]. For an electric discharge at the gas-liquid interface, plasma channels usually form on top of the liquid surface as the liquid acts as counter electrode. Here, reactive species are formed in the gaseous and liquid phases and can easily diffuse into the other phases $[111,112]$.

$$
\begin{aligned}
& \mathrm{H}_{2} \mathrm{O}^{*}+\mathrm{H}_{2} \mathrm{O} \rightarrow \mathrm{H} \cdot+\cdot \mathrm{OH}+\mathrm{H}_{2} \mathrm{O} \\
& \mathrm{e}^{-}+\mathrm{H}_{2} \mathrm{O} \rightarrow \mathrm{H}^{-}+\cdot \mathrm{OH}
\end{aligned}
$$

So far, NTPs were studied for the removal of MCs, ANTX and BMAA [108, 109, 111-115]. Besides the type of reactive species produced in an electric discharge, other parameters also affect the treatment efficacy. Studies on MC-LR removal in a gas-liquid surface discharge showed that a higher operating voltage increased the degradation due to a higher energy input [111, 115], and similar results were shown for the degradation of ANTX in a dielectric barrier discharge in $\mathrm{O}_{2}$ and subsequently bubbling the gas through the sample solution [108]. Here, an increased operating voltage led to higher $\mathrm{O}_{3}$ concentrations, which in turn also resulted in higher $\cdot \mathrm{OH}$ levels in water due to decomposition of dissolved $\mathrm{O}_{3}$ [108]. However, for discharges in air, maximal $\mathrm{O}_{3}$ concentration may not be achieved with the highest voltage, because of increasing $\mathrm{O}_{2}$ consumption in $\mathrm{NO}_{\mathrm{x}}$ reactions and $\mathrm{O}_{3}$ depletion in reactions with $\mathrm{N}$ and $\mathrm{NO}$ at higher voltages [116]. Besides operating voltage, $\mathrm{pH}$ was also shown to affect the MC-LR degradation effectiveness in an $\mathrm{Ar}-$ water surface discharge, in which an acidic $\mathrm{pH}$ was beneficial for the removal [109]. Since MC-LR was expected to be unaffected in the studied $\mathrm{pH}$ range, the $\mathrm{OH}$ concentration was assumed to be reduced under alkaline $\mathrm{pH}$ due to reaction with $\mathrm{OH}^{-}[109]$. The concentrations 
of the formed reactive species can also be increased by higher gas flow rates [115].

The electrode distance also impacts the plasma chemistry, when decreasing distance between high-voltage electrode and the water surface, the energy increases and intensifies the reactions induced by the plasma. For a shorter electrode distance, the transfer time into the solution is reduced especially for short-lived reactive species $[111,112,115]$, where long transfer times can reduce the degradation effectiveness. This is why catalysts have been studied as additives in NTPs to transform long-lived species like $\mathrm{O}_{3}$ and $\mathrm{H}_{2} \mathrm{O}_{2}$ into the more reactive $\cdot \mathrm{OH}$. For example, Mn-doped carbon xerogels not only increase the $\cdot \mathrm{OH}$ concentration, but also adsorb, e.g., MC-LR, thus immobilizing the toxin to enhance reactions with oxidants $[112,114]$. Because electric discharges also generate UV light, photocatalysts like $\mathrm{TiO}_{2}$ have also been studied as additives to increase the formation of $\cdot \mathrm{OH}$ (see the section on "Photocatalysis") [114]. Due to the formation of $\mathrm{H}_{2} \mathrm{O}_{2}$ in water, another alternative is the addition of $\mathrm{Fe}^{2+}$ to yield the Fenton's reagent (see the section on "Fenton oxidation") [115]. Plasma generation, intensive heat and direct electro-physical and -chemical processes at the electrode can lead to corrosion, resulting in the release of metal ions from the electrodes. Correspondingly, electrodes made from catalytic active materials may release, e.g., $\mathrm{Fe}^{2+}$ from stainless steel, which, in combination with $\mathrm{H}_{2} \mathrm{O}_{2}$ produced by the discharge, increases thus . OH formation [107].

Besides pollutant degradation during the actual treatment, plasma treated water has been shown to yield residual-post-treatment-oxidative and microbicidal effects. Up to a few days after exposure to an electric discharge, plasma-treated water still effectively degraded for example BMAA [113]. Although this phenomenon is still not fully elucidated, long-lived reactive species such as $\mathrm{O}_{3}, \mathrm{H}_{2} \mathrm{O}_{2}$ and peroxynitrous acid $\left(\mathrm{HNO}_{3}\right)$ may be responsible for this residual effect [104].

When simulating a real water matrix by adding, for example, $\mathrm{K}_{2} \mathrm{HPO}_{4}, \mathrm{NaNO}_{3}$ or humic acid, degradation of MC-LR was reduced due to competition for $\cdot \mathrm{OH}$ [109]. For ANTX degradation by a dielectric barrier discharge in $\mathrm{O}_{2}, \mathrm{KNO}_{3}, \mathrm{KH}_{2} \mathrm{PO}_{4}$ and glucose were shown to affect the degradation similarly [108].

\section{Sulfate radical-based AOPs}

In $\mathrm{SR}-\mathrm{AOPs}, \mathrm{SO}_{4}{ }^{-}$. is the major reactive species generated from PMS or PS. It is more selective than $\cdot \mathrm{OH}$ and has a higher redox potential at neutral $\mathrm{pH}$ (Table 1), which may make it more suitable for water treatment across a broader pH range [35, 36, 117]. Furthermore, PS and PMS are more stable than $\mathrm{H}_{2} \mathrm{O}_{2}$, increasing precursor transportability across longer distances within water [117]. Moreover, the peroxide bond in PS has a lower bond dissociation energy which requires less energy for radical production compared to $\mathrm{H}_{2} \mathrm{O}_{2}$ [118]. $\mathrm{SO}_{4}{ }^{-}$. can be generated by cleaving the peroxide bond in PMS and PS using energy-based activations through heat, UV irradiation, ultrasound and plasma (Eqs. 24 and 25) [35, 117, 119]. Activation of PMS and PS in redox reactions can be achieved using transition metals in a Fenton-like mechanism (see the section on "Fenton oxidation"), O-functionalized activated carbon, electrochemical processes, radiolysis ( $\mathrm{e}^{-}$formation in water, Eq. 46) and ozone (Eqs. 26-33) [35, 117, 120, 121]. Unexpectedly, phosphate-buffered saline (PBS), a commonly used pH-buffer, was also shown to activate PMS, and the PBS/PMS system effectively degraded model water pollutants Acid Orange 7, rhodamine $b$ and 2,4,6-trichlorophenol [122].

$$
\begin{aligned}
& \mathrm{HSO}_{5}^{-}+\text {energy input } \rightarrow \mathrm{SO}_{4}^{-} \cdot+\cdot \mathrm{OH} \\
& \mathrm{S}_{2} \mathrm{O}_{8}^{2-}+\text { energy input } \rightarrow 2 \mathrm{SO}_{4}^{-} . \\
& \mathrm{HSO}_{5}^{-}+\mathrm{e}^{-} \rightarrow \mathrm{SO}_{4}^{-} \cdot+\cdot \mathrm{OH}\left(\text { or } \mathrm{SO}_{4}^{2-}+\cdot \mathrm{OH}\right) \\
& \mathrm{S}_{2} \mathrm{O}_{8}^{2-}+\mathrm{e}^{-} \rightarrow \mathrm{SO}_{4}^{-} \cdot+\mathrm{SO}_{4}^{2-} \\
& \mathrm{SO}_{4}^{2-} \rightarrow \mathrm{SO}_{4}^{-} \cdot+\mathrm{e}^{-} \\
& \text {AC surface }-\mathrm{OOH}+\mathrm{S}_{2} \mathrm{O}_{8}^{2-} \rightarrow \mathrm{SO}_{4}^{-} \text {. } \\
& +\mathrm{AC} \text { surface }-\mathrm{OO} \cdot+\mathrm{HSO}_{4}^{-} \\
& \text {AC surface }-\mathrm{OH}+\mathrm{S}_{2} \mathrm{O}_{8}^{2-} \rightarrow \mathrm{SO}_{4}^{-} \text {. } \\
& +\mathrm{AC} \text { surface }-\mathrm{O} \cdot+\mathrm{HSO}_{4}^{-} \\
& \mathrm{SO}_{5}^{2-}+\mathrm{O}_{3} \rightarrow \mathrm{SO}_{5}^{-} \cdot+\mathrm{O}_{3}^{-} \cdot\left(\text { or } \mathrm{SO}_{4}^{2-}+2 \mathrm{O}_{2}\right) \\
& \mathrm{SO}_{5}^{-} \cdot+\mathrm{O}_{3} \rightarrow \mathrm{SO}_{4}^{-} \cdot+2 \mathrm{O}_{2} \\
& \mathrm{SO}_{5}^{-} \cdot \rightarrow 2 \mathrm{SO}_{4}^{-} \cdot+\mathrm{O}_{2}\left(\text { or } \mathrm{S}_{2} \mathrm{O}_{8}^{2-}+\mathrm{O}_{2}\right) \\
& \mathrm{O}_{3}^{-} \cdot+\mathrm{H}_{2} \mathrm{O} \rightarrow \cdot \mathrm{OH}+\mathrm{OH}^{-}+\mathrm{O}_{2} \\
& \mathrm{SO}_{4}^{-} \cdot+\mathrm{H}_{2} \mathrm{O} \rightarrow \mathrm{SO}_{4}^{2-}+\cdot \mathrm{OH}+\mathrm{H}^{+} \\
& \mathrm{SO}_{4}^{-} \cdot+\mathrm{OH}^{-} \rightarrow \mathrm{SO}_{4}^{2-}+\cdot \mathrm{OH} \\
& \mathrm{SO}_{4}^{-} \cdot+\cdot \mathrm{OH} \rightarrow \mathrm{HSO}_{5}^{-}
\end{aligned}
$$




$$
\begin{aligned}
& \mathrm{HSO}_{4}^{-}+\mathrm{OH} \cdot \rightarrow \mathrm{SO}_{4}^{-} \cdot+\mathrm{H}_{2} \mathrm{O} \\
& \mathrm{H}_{2} \mathrm{SO}_{4}+\cdot \mathrm{OH} \rightarrow \mathrm{SO}_{4}^{-} \cdot+\mathrm{H}_{3} \mathrm{O}^{+}
\end{aligned}
$$

SR-AOPs are a worthy alternative to $\mathrm{OH}$-based AOPs due to the simultaneous generation of $\cdot \mathrm{OH}$ as secondary radical when PMS is used as precursor (Eqs. 24 and 26), in the presence of water (Eq. 35), under alkaline conditions (Eq. 36) or when PMS is activated using $\mathrm{O}_{3}$ (Eqs. 31 to 34$)$. Consequently, $\cdot \mathrm{OH}$ is the primary reactive species at alkaline $\mathrm{pH}$, whereas $\mathrm{SO}_{4}{ }^{-}$. is the dominant radical at acidic $\mathrm{pH}$. At neutral $\mathrm{pH}$, both radicals equally contribute to pollutant oxidation $[117,121]$. The reaction of both radicals forms PMS (Eq. 37), which in turn can again be activated to generate $\mathrm{SO}_{4}{ }^{-}$. and $\cdot \mathrm{OH}$ [117]. In addition, the reaction of $\mathrm{OH}$ with $\mathrm{HSO}_{4}{ }^{-}$or $\mathrm{H}_{2} \mathrm{SO}_{4}$ can also produce $\mathrm{SO}_{4}{ }^{-}$. (Eqs. 38 and 39) [120].

$\mathrm{SO}_{4}{ }^{-}$. generally reacts with organic pollutants in three distinctive routes: (i) via hydrogen abstraction from $\mathrm{C}-\mathrm{H}$ bonds, (ii) via addition to unsaturated bonds and (iii) via electron transfer reactions from carboxylates, amines and aromatic compounds [35]. The third mechanism promotes decarboxylation, which, besides for SR-AOPs, has only been reported for UV-based degradation of cyanotoxins [56, 83, 84, 121, 123]. PMS and PS also function as oxidants, but $\mathrm{SO}_{4}{ }^{-}$. is usually more effective and faster given its substantially higher redox potential (Table 1). PS is usually preferred over PMS due to its higher stability, water solubility, photosensitivity and is more frequently used in standard methods and commercial instruments [35].

SR-AOPs have been studied for the removal of MCs, CYN and ANTX, mainly focusing on UV and catalyst activation [36, 40, 41, 124]. Even without activation, high removal ( $\geq 90 \%$ ) of MC-LR and CYN was achieved after $>500$ min of treatment for PS and $>100$ min of treatment for PMS, while ANTX was almost unaffected by PMS without activation. However, when UV radiation was added, degradation of these three toxins became more effective [40, 41, 124]. MC-LR and CYN degradation efficacy was in order of UV/PS $>\mathrm{UV} / \mathrm{PMS}>\mathrm{UV} / \mathrm{H}_{2} \mathrm{O}_{2}[40$, 41]. Due to its structure, MC-LR was faster degraded than CYN because it provides more moieties prone to radical attack [40, 41]. Studies with different MC variants showed that under UV only, degradation increased following MC-LR $<-R R<-Y R<-L A$, while the differences were only small in the presence of PMS, PS or $\mathrm{H}_{2} \mathrm{O}_{2}$ [41]. Similar to MC-LR and CYN, degradation efficacies for MC-LA, -RR and -YR followed UV/PS $>$ UV/PMS $>$ UV/ $\mathrm{H}_{2} \mathrm{O}_{2}>$ UV-only [41]. Similar to other photolytic AOPs, the wavelength influenced the degradation efficacy in UV-activated SR-AOPs. For example, ANTX removal increased when the wavelength was decreased from 290 to $260 \mathrm{~nm}$ [124]. A follow-up experiment with radical quenchers revealed that under the experimental conditions used, ANTX degradation was dominated by $\mathrm{SO}_{4}{ }^{-}$. [124].

In contrast to UV activation, MC-LR degradation efficacy was in a different order: $\mathrm{Co}^{2+} / \mathrm{PMS}$ $(\mathrm{pH}=5.8)>\mathrm{Fe}^{2+} / \mathrm{H}_{2} \mathrm{O}_{2} \quad(\mathrm{pH}=3) \gg \mathrm{Ag}^{+} / \mathrm{PS} \quad(\mathrm{pH}=5.8)$ because PMS accepts $\mathrm{e}^{-}$more easily than $\mathrm{H}_{2} \mathrm{O}_{2}$ and PS [36]. Moreover, activation of PS requires substantially higher transition metal concentrations [36, 125].

MC-LR degradation was further improved by addition of $\mathrm{TiO}_{2}$ to the UV/PMS or UV/PS system due to photolytic and photocatalytic (see the section on "Photocatalysis") production of $\mathrm{SO}_{4}{ }^{-} \cdot$ and $\cdot \mathrm{OH}$ [126], and addition of transition metals can promote (photo-) Fenton-like mechanisms. For instance, $\mathrm{Cu}^{2+}$ and $\mathrm{Fe}^{2+}$ improved CYN degradation by UV/PMS, even in the presence of NOM [40]. Similar results were observed for ANTX, and again, $\mathrm{UV} / \mathrm{PMS} / \mathrm{Cu}^{2+}$ yielded better results compared to UV/ $\mathrm{PMS} / \mathrm{Fe}^{2+}[124]$. Besides type and properties of the activation mechanism, an increase in the oxidant concentration seems to generally increase the degradation rate due to the formation of more reactive species [36, 40, 124].

As for other AOPs, water quality parameters may considerably influence cyanotoxin degradation by SR-AOPs. Reaction rate constants of $\mathrm{SO}_{4}{ }^{-}$. with $\mathrm{NOM}$ were shown to be two orders of magnitude lower compared to rate constants of $\cdot \mathrm{OH}$ with NOM but quenching effects can still occur and particularly depend on NOM composition and concentration [40, 125]. For ANTX degradation by UV/PMS, $\leq 2 \mathrm{mg} \mathrm{L}^{-1}$ of NOM was shown to improve toxin removal due to photosensitization. But at higher NOM concentrations, radical scavenging outbalanced this photosensitizing effect, and inhibited ANTX degradation [124]. Interestingly, humic acid and quinones, which are active functional humic acid moieties, were shown to activate PS and effectively degraded for example PCB28 [127]. Hence, NOM may not only act as photosensitizer, but also certain moieties may eventually react with PS to produce $\mathrm{SO}_{4}^{-}$.

Besides NOM, alkalinity can also act as radical scavenger, especially since carbonate and bicarbonate concentrations $\left(\mathrm{mg} \mathrm{L}^{-1}\right)$ highly exceed toxin concentrations $\left(\mu \mathrm{g} \mathrm{L}^{-1}\right)$ in surface water $[40,124]$. The $\mathrm{pH}$ of the treated water is another important factor which determines the speciation of toxins, catalysts as well as oxidants. In UV/SR-AOPs at acidic conditions around $\mathrm{pH} \mathrm{3,} \mathrm{MC-LR}$ degradation rate constants substantial increased compared to unbuffered solutions with $\mathrm{pH} 4.8$ and $\mathrm{pH} 6.4$ for PMS and PS, respectively [36]. ANTX removal by UV/ PMS, on the other hand, was most effective at $\mathrm{pH} 6.4$ and decreased under more acidic $(\mathrm{pH} 3.0)$ and alkaline conditions ( $\mathrm{pH}$ 8.0) [124]. However, when the $\mathrm{Co}^{2+} /$ 
PMS system was acidified, MC-LR removal decreased from $100 \%$ after $5 \mathrm{~min}$ at $\mathrm{pH}=5.8$ to $27 \%$ after $60 \mathrm{~min}$ at $\mathrm{pH}=3$ and became substantially less effective compared to the Fenton reagent at $\mathrm{pH}=3$ [36]. This decrease in MC-LR degradation is rather caused by inhibition of PMS decomposition than reduced reactivity of $\mathrm{SO}_{4}{ }^{-}$. at acidic $\mathrm{pH}$.

\section{Electrochemical oxidation}

In an electrolytic process, pollutant oxidation can occur directly, via electron transfer to the anode surface and indirectly, via electrochemically formed reactive species including $\cdot \mathrm{OH}, \mathrm{H}_{2} \mathrm{O}_{2}, \mathrm{O}_{3}$ (Eqs. 40-42) and others depending on electrolyte composition, which is why it is also referred to as electrochemical AOP (EAOP). Based on the setup of the treatment cell, EAOPs can be grouped into four different classes. The simplest is direct and indirect anodic oxidation (AO) of a pollutant. At neutral or acidic $\mathrm{pH}$ and in the presence of air or $\mathrm{O}_{2}, \mathrm{H}_{2} \mathrm{O}_{2}$ can additionally be generated by cathodic reduction (Eq. 43, AO- $\mathrm{H}_{2} \mathrm{O}_{2}$ ). To further increase the treatment, $\mathrm{Fe}^{2+}$ can be added to yield $\cdot \mathrm{OH}$ (electro-Fenton, EF). In EF, continuous cathodic electrogeneration of $\mathrm{H}_{2} \mathrm{O}_{2}$ and cathodic $\mathrm{Fe}^{3+}$ regeneration to $\mathrm{Fe}^{2+}$ (Eq. 44) perpetually produce the Fenton's reagent if an undivided cell is used (see the section on "Fenton oxidation"). If EF is exposed to light (photoelectro-Fenton, PEF), the Fenton reaction itself can be improved by photolytic $\mathrm{H}_{2} \mathrm{O}_{2}$ cleavage to $\cdot \mathrm{OH}$ (see the sections on "Photolysis" and "Fenton oxidation"). In EAOPs, non-active anodes with high $\mathrm{O}_{2}$-overpotential (potential for $\mathrm{O}_{2}$ development) such as boron-doped diamond anodes (BDD) are usually employed. The higher the $\mathrm{O}_{2}$-overpotential, the weaker is the physisorption of .OH to the anode surface, which, in turn, leads to higher .OH availability in the solution [90].

$$
\begin{aligned}
& \mathrm{M}+\mathrm{H}_{2} \mathrm{O} \rightarrow \mathrm{M}(\cdot \mathrm{OH})+\mathrm{H}^{+}+\mathrm{e}^{-} \\
& 2 \mathrm{M}(\cdot \mathrm{OH}) \rightarrow 2 \mathrm{MO}+\mathrm{H}_{2} \mathrm{O}_{2} \\
& 3 \mathrm{H}_{2} \mathrm{O} \rightarrow \mathrm{O}_{3}+6 \mathrm{H}^{+}+6 \mathrm{e}^{-} \\
& \mathrm{O}_{2(\mathrm{~g})}+2 \mathrm{H}^{+}+2 \mathrm{e}^{-} \rightarrow \mathrm{H}_{2} \mathrm{O}_{2} \\
& \mathrm{Fe}^{3+}+\mathrm{e}^{-} \rightarrow \mathrm{Fe}^{2+}
\end{aligned}
$$

Here, $\mathrm{M}(\cdot \mathrm{OH})$ means $\cdot \mathrm{OH}$ is physisorbed to the anode surface M. Electrochemical oxidation of MC, NOD and CYN has been investigated with different electrodes and treatment parameters $[120,128-131]$. One of the most influential factors in terms of degradation effectiveness and operating costs are the electrodes used in EAOPs. BDDs are often used due to their high $\mathrm{O}_{2}$-overpotential, and regardless of the used electrolytes, achieved higher MC-LR degradation compared to mixed metal oxide electrodes such as $\mathrm{IrO}_{2}-\mathrm{Ta}_{2} \mathrm{O}_{5} / \mathrm{Ti}$ [130]. Even when coated onto Ti as carrier material, MC-LR removal was in order of Ti/BDD $>\mathrm{Ti} / \mathrm{IrO}_{2}>\mathrm{Ti} / \mathrm{Pt}>\mathrm{Ti} / \mathrm{SnO}_{2}$ under otherwise same conditions [129]. However, BDD electrodes are costly and cheaper alternatives such as electrodes synthesized from nanosized $\mathrm{TiO}_{2}$ coated onto a graphite carrier were efficient for MC-LR degradation [128].

Besides electrode material, the applied current affects the degradation efficacy with higher current densities resulting in higher toxin removal $[120,129]$. The efficacy of an EAOP also depends on the electrolyte composition and its electric conductivity. For instance, MC-LR degradation in filtered lake and tap water improved after increasing the conductivity by adding $\mathrm{Na}_{2} \mathrm{CO}_{3}[128,132]$. The electrolyte composition also dictates which reactive species are produced and thus, EAOPs can be tailored toward specific requirements and pollutants. Although the order of cyanotoxin removal for electrolyte salts is usually $\mathrm{Cl}^{-}>\mathrm{SO}_{4}{ }^{2-}>\mathrm{NO}_{3}{ }^{-}>\mathrm{CO}_{3}{ }^{2-}[129,133,134]$, $\mathrm{SO}_{4}{ }^{2-}$ is often suggested as best choice because of lower production of toxic disinfection byproducts from halogen-based electrolytes and avoidance of eutrophication from N- and P-based electrolytes [129, 134]. The risk of halogenated byproducts can be reduced at low salt concentrations and higher current densities but this would, in turn, increase electric energy demand [133].

Influence of water parameters on degradation of cyanotoxins by EAOPs has only scarcely been investigated but studies showed NOM scavenging of produced reactive species [130]. For the effect of $\mathrm{pH}$ on MC-LR degradation by EAOPs, contradicting observations were reported. While Zhang et al. [135] found no significant effect on MC-LR degradation rate constants across a range of $\mathrm{pH}$ from 5 to 9, Zhou et al. [130] observed higher MC-LR degradation at lower $\mathrm{pH}$. Both studies used different electrolytes $\left(\mathrm{NaNO}_{3}\right.$ and $\mathrm{Na}_{2} \mathrm{SO}_{4}$, respectively), which may explain the different results. In a photoelectrocatalytic treatment of $\mathrm{MC}$ - $\mathrm{LR}$ using $\mathrm{Ag} / \mathrm{AgCl} / \mathrm{TiO}_{2}$ nanotubes electrodes, the degradation appeared to be $\mathrm{pH}$-dependent due to more effective adsorption to $\mathrm{TiO}_{2}$ under acidic $\mathrm{pH}$ and a lower potential level of the valence band of the photoelectrode at alkaline $\mathrm{pH}$ which decreased MC-LR oxidation [89].

\section{Sonolysis}

In sonolysis, ultrasound is used to form liquid-free cavities, i.e., bubbles, in a liquid medium due to rapid changes in pressure created by an oscillating ultrasonic wave. When these bubbles collapse, high energy is released 
in form of average bubble temperatures of $4200 \mathrm{~K}$ and pressures of $500 \mathrm{~atm}$ [10]. Volatile and nonpolar pollutants can be degraded in the cavitation by direct pyrolysis, thermolysis, hydrolysis or hydroxylation with $\cdot \mathrm{OH}$ formed from the gas-phase thermolysis of water (Eq. 45) [10]. Besides acoustically, i.e., due to ultrasound, cavities can also be formed hydrodynamically, where cavities are generated when a liquid is forced to flow under reduced pressure which leads to a local drop of the static pressure to below the critical value. This can be achieved, e.g., by a local increase of the flow rate, flow line curvature or channel constrictions [136].

$$
\mathrm{H}_{2} \mathrm{O} \stackrel{))}{\rightarrow} \mathrm{H} \cdot+\cdot \mathrm{OH}
$$

Non-volatiles and compounds with an amphiphilic or less polar character are degraded in the interfacial boundary layer between the bubble and bulk where temperatures of up to $2000 \mathrm{~K}$ and high. $\mathrm{OH}$ concentrations are present. Non-volatile and polar compounds are degraded in the bulk aqueous phase by $\mathrm{OH}$ migrating away from the cavitation or $\mathrm{H}_{2} \mathrm{O}_{2}$ formed in the system [10]. The degradation effectiveness thus depends on the pollutant's physico-chemical properties and preferred chemical environment, i.e., polar/nonpolar or volatile/ non-volatile [137]. Besides pyrolysis, thermolysis and chemical reactions, shockwaves and high shear forces are released, which can be utilized to, e.g., destruct and lyse cyanobacterial cells [10]. Depending on the pollutant and desired processes, the ultrasonic wave frequency can be adjusted to favor formation and reactions of $\cdot \mathrm{OH}(200-$ $600 \mathrm{~Hz})$ or higher temperatures and pressures $(<200 \mathrm{~Hz})$ [10].

So far, studies focused solely on the sonolytic treatment of MCs [137-140], and the highest degradation was observed in the approximate frequency range of $150-410 \mathrm{kHz}$. Both lower and higher frequencies resulted in less effective degradation due to lower $\cdot \mathrm{OH}$ concentrations [139, 140]. An increase in the applied power yielded higher MC degradation but the degradation rate was substantially faster only in the first few minutes of the treatment and later became undistinguishable when comparing 30, 60 and $90 \mathrm{~W}$ [140]. In addition to the power (in W) or intensity (in $\mathrm{W} \mathrm{cm}^{-2}$ ), the distribution of the ultrasound within the treated area affects the treatment efficiency [10]. A study with different radical scavengers showed that about $39 \%$ of the degradation was achieved by. $\mathrm{OH}$ in the bulk solution and about $35 \%$ degradation was achieved by $\cdot \mathrm{OH}$ at the bubble interface [138]. Due to its non-volatile and polar character, MC-LR is not expected to reside inside the cavity but the nonpolar Adda side chain most likely resides in the bubble interfacial region [138]. MC-LR degradation can be improved under acidic conditions that increase the hydrophobicity of the Adda moiety [137]. Some MC degradation can also be attributed to hydrolysis and pyrolysis in the interfacial region, while shear forces are unlikely to cause mechanical destruction of the toxin [138]. Also, $\mathrm{H}_{2} \mathrm{O}_{2}$ is produced in sonolytic processes and can act as a quencher reducing the MC-LR degradation, it can simply be overcome by adding $\mathrm{Fe}^{2+}$, which eliminates $\mathrm{H}_{2} \mathrm{O}_{2}$ and further increases $\mathrm{OH}$ formation (for the section on “Fenton oxidation") [137]. Interestingly, NOM, e.g., from cyanobacterial cells, appeared to only have a small effect on the treatment effectivity [138].

\section{Radiolysis}

Radiolysis uses ionizing radiation with energies of approximately $100 \mathrm{eV}$, which is substantially higher than energies usually required for ionization of organic compounds $(<15 \mathrm{eV})$ and cleavage of chemical bonds $(1-5 \mathrm{eV})$ [141]. Commonly used radiation sources are radionuclides and electrostatic accelerators emitting $\gamma$-radiation and electron beams, respectively [141, 142]. Radiolysis requires specialized instrumentation and expertise which are rare in water treatment facilities. However, because it produces a range of reactive chemical species in water and no precursors or other additives are needed, it can be useful for in-depth studies of oxidation mechanisms. The radiolytic decomposition of water is shown in the following equation (radiation yields $\mathrm{G}$ (in $\mu \mathrm{mol} \mathrm{J}{ }^{-1}$ ) are given in parentheses) $[142,143]$ :

$$
\begin{aligned}
& \mathrm{H}_{2} \mathrm{O} \stackrel{\mathrm{rad}}{\rightarrow} \mathrm{e}_{\mathrm{aq}}^{-}(0.27)+\cdot \mathrm{OH}(0.28)+\mathrm{H} \cdot(0.06)+\mathrm{H}_{2} \\
& (0.05)+\mathrm{H}_{2} \mathrm{O}_{2}(0.07)+\mathrm{H}_{3} \mathrm{O}^{+}(0.27)+\mathrm{HO}_{2} \cdot(0.003)
\end{aligned}
$$

So far, only studies with MCs, CYN and ANTX used radiolysis [19, 143-145]. The rate constants for $\cdot \mathrm{OH}$ attacking specific functional moieties of MC-LR were determined in the following order: benzene ring in Adda moiety $\left(10^{10} \mathrm{M}^{-1} \mathrm{~s}^{-1}\right) \geq$ diene in Adda moiety $\left(10^{10}\right.$ to $\left.10^{9} \mathrm{M}^{-1} \mathrm{~s}^{-1}\right)>$ aliphatic hydrogens $\left(10^{8} \mathrm{M}^{-1} \mathrm{~s}^{-1}\right)$ [143]. Although hydrogen abstraction is the slowest reaction pathway, it is still assumed to be significant due the large number of $>50$ potential reaction sites [143]. The overall calculated rate constant for the reaction of $\cdot \mathrm{OH}$ with MC-LR (using literature values for appropriate surrogates, mainly amino acids) $2.1 \times 10^{10} \mathrm{M}^{-1} \mathrm{~s}^{-1}$ [143] is very close to the experimentally derived rate constant $2.3 \times 10^{10} \mathrm{M}^{-1} \mathrm{~s}^{-1}$, for which the $\cdot \mathrm{OH}$ attack at the Adda group accounted for almost $70 \%$ in the model [143]. For CYN, the overall rate constant of $5.1 \times 10^{9} \mathrm{M}^{-1} \mathrm{~s}^{-1}$ was measured with the uracil side chain being the main susceptible moiety for $\cdot \mathrm{OH}$ attacks (84\%), whereas the attack at the guanidine group is less important [61]. In another 
study, the rate constants for the reaction of $\cdot \mathrm{OH}$ with $\mathrm{MC}-\mathrm{LR}$ and $\mathrm{CYN}$ using radiolysis were determined to be within the same order of magnitude, $1.1 \times 10^{10} \mathrm{M}^{-1} \mathrm{~s}^{-1}$ and $5.5 \times 10^{9} \mathrm{M}^{-1} \mathrm{~s}^{-1}$, respectively [19]. The negligibly different factors are most likely caused by differences in the experimental conditions and methodologies used in the different studies. The order of rate constants was found to be MC-LR>CYN > ANTX, which corresponds to the toxins' molecular size and number of $\mathrm{H}$-atoms that can be abstracted by $\cdot \mathrm{OH}[19]$.

The efficiency of radiolytic treatment of MCs is dosedependent and can be improved by adding $\mathrm{Na}_{2} \mathrm{CO}_{3}$ or $\mathrm{H}_{2} \mathrm{O}_{2}$ which leads to the formation of $\mathrm{HO}_{2}$. and $\cdot \mathrm{OH}$, respectively [144]. In contrast, nitrite and nitrate were shown to decrease the removal due to scavenging of $\cdot \mathrm{OH}$ [144]. Furthermore, since $\cdot \mathrm{OH}$ is a non-selective oxidant, radiolytic treatment can obviously be impacted by water quality parameters such as NOM $[19,145]$.

\section{Comparison of AOPs}

\section{Degradation efficiency of AOPs}

When comparing different AOPs, especially considering their application in large-scale water treatment, degradation efficiency is among the most crucial parameters. It relates the required energy, oxidant or catalyst dose to the efficacy of the treatment. For energy efficiency of AOPs, electrical energy per order $\left(E_{\mathrm{EO}}\right)$ is often chosen as a figure of merit. $E_{\mathrm{EO}}$ is defined as electrical energy in $\mathrm{kWh}$ required to remove a pollutant by 1 order of magnitude, i.e., $90 \%$, in $1 \mathrm{~m}^{3}$ of water [146]. In case of oxidants or catalysts, the "stored electric energy" of a compound can be calculated based on prices for electric energy (price per $\mathrm{kWh}$ ) and the respective compound (price per $\mathrm{kg}$ ) [147].

Based on a comprehensive review on AOPs for water treatment and data on their energy efficiency reported in peer-reviewed literature, Miklos et al. [146] grouped established and emerging AOPs according to their $E_{\mathrm{EO}}$ values (Fig. 3). According to this review, most reported $E_{\mathrm{EO}}$ values did not include auxiliary oxidants or catalysts in the calculations. The first group comprises AOPs with median $E_{\mathrm{EO}}$ values of $<1 \mathrm{kWh} \mathrm{m}^{-3}$ which represents a realistic range for full-scale application. The second group includes AOPs with median $E_{\mathrm{EO}}$ values of 1-100 $\mathrm{kWh} \mathrm{m}^{-3}$ which is energy extensive but in case of specific problems, these AOPs may provide an attractive solution, also for eventual large-scale applications. The last group contains AOPs with median $E_{\mathrm{EO}}$ values of $>100 \mathrm{kWh} \mathrm{m}^{-3}$ which are currently not considered to be energy efficient [146]. Nevertheless, future developments may lead to optimization and reduction of energy demands and related costs.

$E_{\mathrm{EO}}$ values for cyanotoxin removal by AOPs have only rarely been reported. For $\mathrm{UV} / \mathrm{H}_{2} \mathrm{O}_{2}$ treatment of MC-LR and $\mathrm{CYN}, E_{\mathrm{EO}}$ values were $4.5 \times 10^{-3}-6.1 \times 10^{-3}$ and $1.6 \times 10^{-3} \mathrm{kWh} \mathrm{m}^{-3}$, respectively [40, 148]. For UV/PMS and UV/PS treatment, $E_{\mathrm{EO}}$ values were estimated to range from $10^{-4}$ to $10^{-5} \mathrm{kWh} \mathrm{m}^{-3}$, respectively, for CYN, and 0.7 and $0.2 \mathrm{kWh} \mathrm{m}^{-3}$, respectively, for MC-LR $[40,126]$. For electrochemical oxidation of MC-LR, the $E_{\mathrm{EO}}$ ranged from 48 to $67 \mathrm{kWh} \mathrm{m}^{-3}$ depending on electrode material [129]. These $E_{\mathrm{EO}}$ values seem to agree with the results by Miklos et al. [146]. However, for $\mathrm{UV} / \mathrm{TiO}_{2}$ treatment, low $E_{\mathrm{EO}}$ values, approximately 0.08 to $0.14 \mathrm{kWh} \mathrm{m}^{-3}$, were reported for MC-LR and 0.03 to $0.015 \mathrm{kWh} \mathrm{m}^{-3}$ for MC-LR, -LA and -RR in two independent studies [126, 149] which are at least 2-3 orders of magnitude lower compared to the results by Miklos et al. [146]. Although energy-efficient UV-LEDs were used in the second study [149], the light source itself seems not to have a substantial effect since demanding UV xenon lamps were used in the study of Antoniou et al. [126].

Interestingly, process capacity, i.e., laboratory-, pilot- and full-scale application, was inversely correlated with $E_{\mathrm{EO}}$ values which decreased with increasing

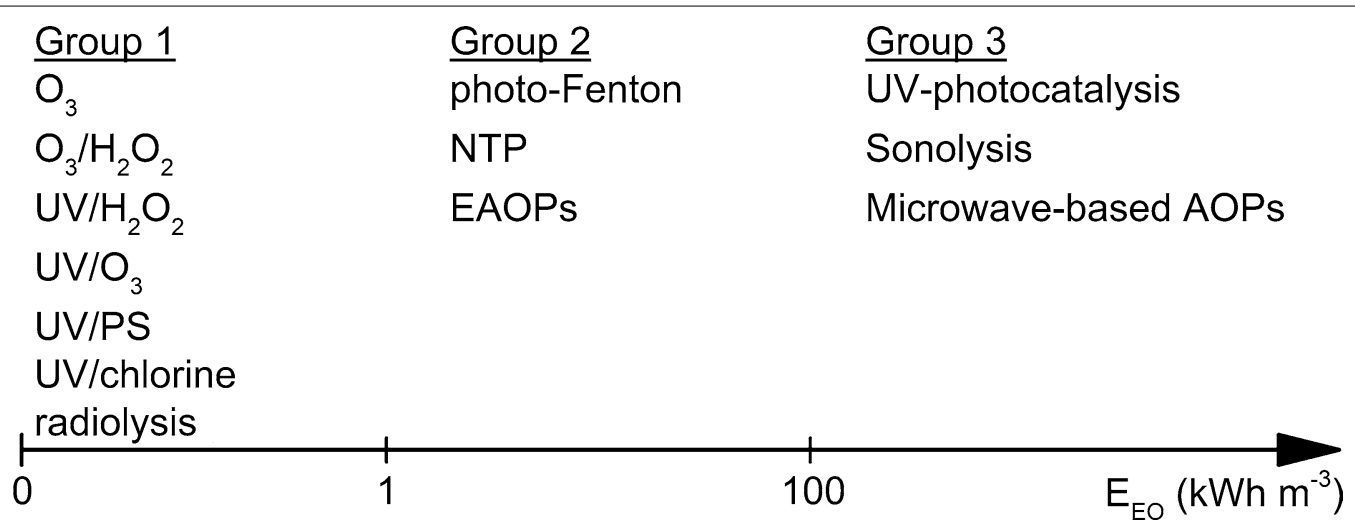

Fig. 3 Grouping of established and emerging AOPs according to their median $E_{\mathrm{EO}}$ values (based on the review by Miklos et al. [146]) 
process capacity. This indicates that up-scaling apparently improves energy efficiency and the demands derived from laboratory-scale experiments may not be correctly translated to full-scale processes. Furthermore, water quality (pure, drinking, ground- and wastewater) did not affect $E_{\mathrm{EO}}$ values significantly, even when relevant parameters such as NOM, UV transmittance and turbidity were considered [146].

\section{Potential of disinfection byproduct formation}

An important aspect is the formation of toxic disinfection byproducts (DBPs) during AOP treatment, where halogenated organic and inorganic compounds such as trihalomethans, haloacetic acids, haloacetronitrils, chlorates, bromates and others are of special concern [146]. Because of their toxicity, the WHO recommended guideline values for several DBPs like chloroform $\left(300 \mu \mathrm{g} \mathrm{L}^{-1}\right)$, bromoform $\left(100 \mu \mathrm{g} \mathrm{L}^{-1}\right)$, perchlorate $\left(70 \mu \mathrm{g} \mathrm{L}^{-1}\right)$ and bromate $\left(10 \mu \mathrm{g} \mathrm{L}^{-1}\right)$ [150-152]. DBP formation depends on the employed AOP as well as the water matrix, i.e., presence of nitrogen, organic matter and halogens [146].

Formation of bromate is relevant for $\mathrm{O}_{3}$ and $\mathrm{O}_{3}$-based AOPs, where up to $50 \%$ of bromide (at concentrations $>100 \mu \mathrm{g} \mathrm{L}^{-1}$ ) can be converted to bromate [146], and $\cdot \mathrm{OH}$ may promote bromate formation by about $30-70 \%$ [153]. Attenuation is possible by decreasing $\mathrm{pH}$, $\mathrm{O}_{3}$ or bromide concentration and in the presence of $\mathrm{H}_{2} \mathrm{O}_{2}$ $[153,154]$. Chlorate formation by $\mathrm{O}_{3}$ and $\mathrm{O}_{3}$-based AOPs may only be relevant if the treatment contains a pre-chlorination step [146].

In most $\cdot \mathrm{OH}$-dominated AOPs, bromate formation can usually be neglected in the abundance of organic matter or $\mathrm{H}_{2} \mathrm{O}_{2}$ due to radical quenching $[146,154]$. Chlorate and perchlorate are only produced under specific conditions when reactive chlorine species are abundant, which may further react with organic matter to form halogenated DBPs. Generally, DBP formation by $\cdot \mathrm{OH}$ is considered to be noncritical with the exception for some approaches like high-density $\cdot \mathrm{OH}$ generation at electrode surfaces in EAOPs [146].

For SR-AOPs, bromate formation is effectively inhibited by small concentrations of organic matter $[146,154]$ but reactions of $\mathrm{SO}_{4}{ }^{-}$. with chloride may produce $\mathrm{Cl}$. and subsequently chlorate at $\mathrm{pH}<5$ [154].

UV irradiation does not produce inorganic DBPs but can form nitrite due to photolysis of nitrate which may subsequently lead to the formation of nitrated aromatic compounds. In UV/chlorine processes, organic halides can be formed at alkaline $\mathrm{pH}$ and chloride concentrations of $>1 \mathrm{~g} \mathrm{~L}^{-1}[146]$.
Practical, environmental and economic considerations Besides treatment efficiency, other relevant factors may impact the choice of AOP for a specific situation. Table 2 summarizes advantages, disadvantages and potential ways to overcome certain drawbacks of discussed AOPs considering mainly practical, environmental and economic aspects.

\section{Conclusion}

Cyanobacterial blooms and toxins evidently pose a serious risk to drinking water and human health. Although cells and intracellular toxins can effectively be removed by conventional treatment, dissolved cyanotoxins require more advanced treatment such as AOPs based on reactive species including $\cdot \mathrm{OH}, \mathrm{SO}_{4}{ }^{-}$. and other mechanisms.

However, treatment efficacy is strongly impacted by water quality parameters, where, for example, NOM, alkalinity and $\mathrm{pH}$ can impact reactive species stability and abundance, while $\mathrm{pH}$ also determines toxin speciation and susceptibility to degradation. Furthermore, $\mathrm{NOM}$, chloride and bromide may function as precursors for toxic DBPs. Hence, AOPs, especially their process parameters, need to be optimized for individual situations also considering economic aspects such as operational and maintenance costs.

So far, most studies focused on single toxin removal in either pure or "simulated surface water". More research is thus needed on the degradation of environmentally relevant cyanotoxin mixtures, which are likely to co-occur in the environment, in actual surface water or water withdrawn from a drinking water treatment process prior to the oxidation step. Further, various degradation products have been tentatively identified in different studies but eventual residual toxicity of the treated cyanotoxin solution is rarely examined. Adequate toxicological assays can be recommended to ensure that toxins are not only degraded but also actually detoxified, especially if degradation products are not analyzed or if DBPs are likely to be produced during the treatment process.

It was also found that efficiency as well as estimated operational and maintenance costs of an AOP at laboratory-scale do not easily translate to full-scale treatment. Hence, there is a need for more research of pilot- and full-scale applications to promote AOPs and provide essential information to drinking water treatment plant operators. For instance, photocatalysis for water treatment has been studied for decades but there are still not many, if any at all, full-scale drinking water treatment applications.

Finally, since cyanotoxins will most likely not be the only challenge to a drinking water treatment facility, a combination of different treatment methods, including 


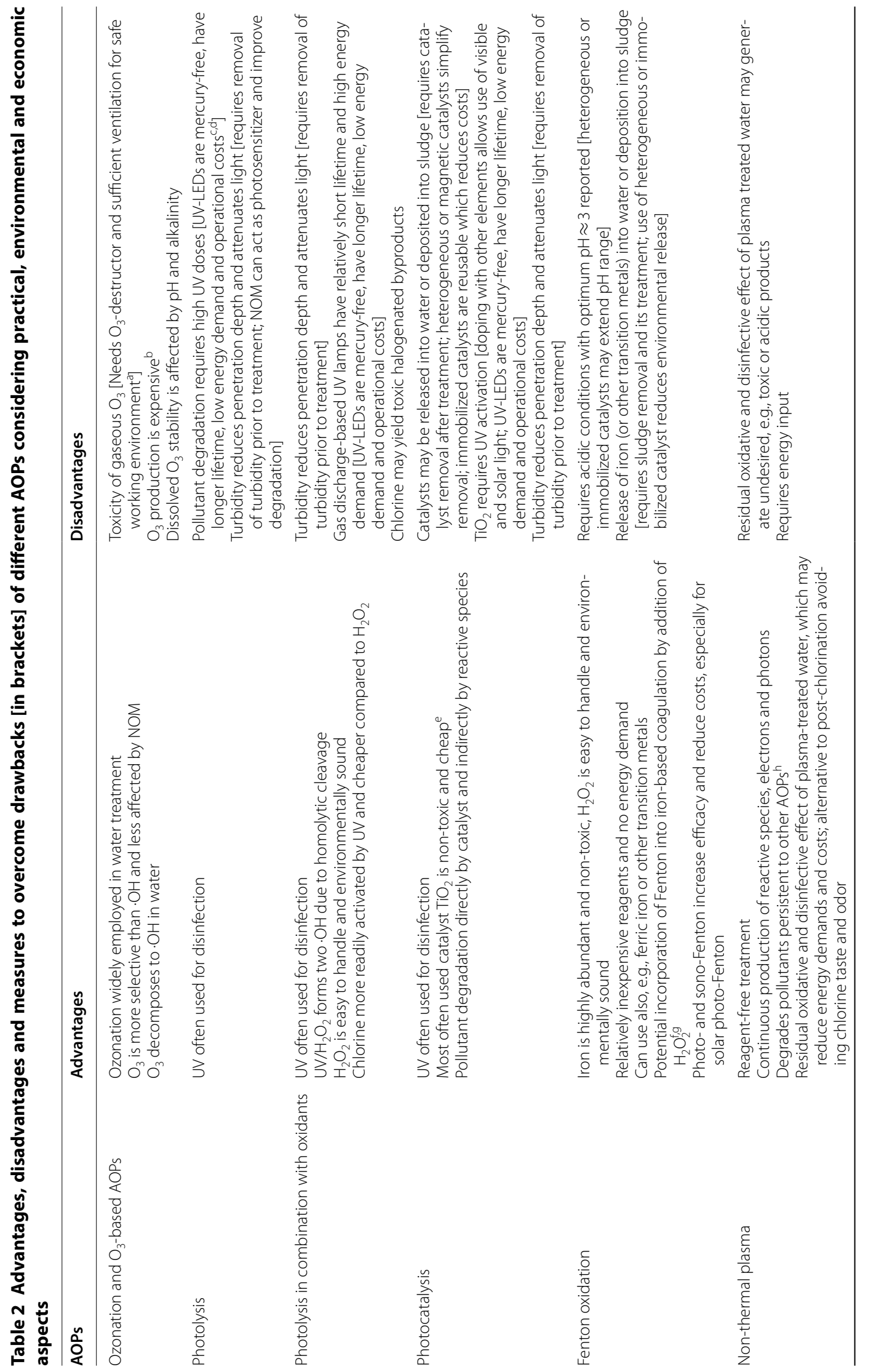




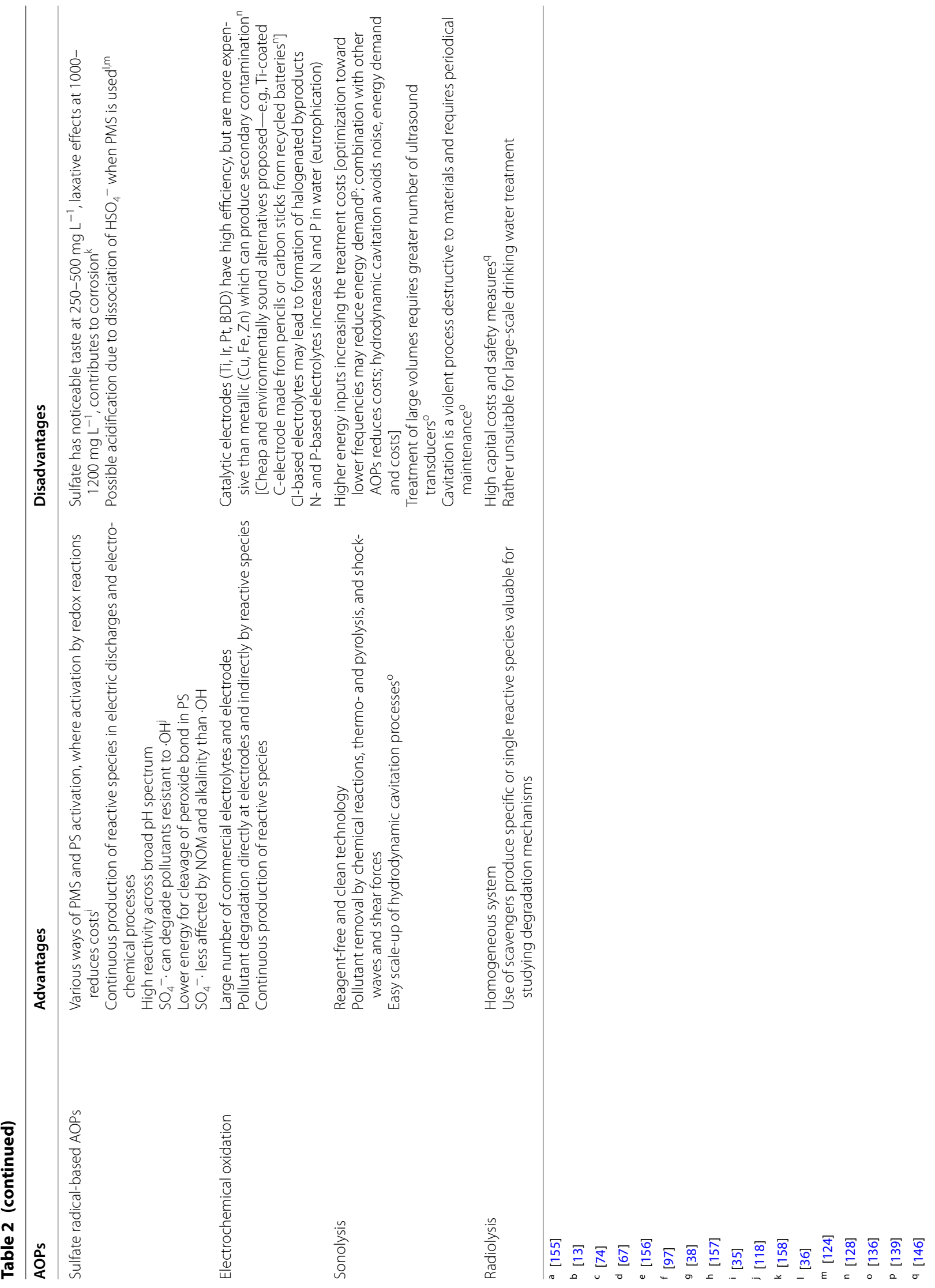




\section{different AOPs, in a multi-barrier approach needs to be considered to produce harmless, high-quality drinking water.}

\begin{abstract}
Abbreviations
A: Alanine; AC: Activated carbon; ANTX: Anatoxin-a; AO: Anodic oxidation; AOP: Advanced oxidation process; BDD: Boron-doped diamond; BMAA: $\beta$-N-methylamino-L-alanine; CYN: Cylindrospermopsin; DBP: Disinfection byproduct; EAOP: Electrochemical advanced oxidation process; $E_{\mathrm{E}}$ : Electrical energy per order; EF: Electro-Fenton; GTX: Gonyautoxin; GV: Guideline value; L: Leucine; LED: Light-emitting diode; MC: Microcystin; NOD: Nodularin; NOM: Natural organic matter; NTP: Non-thermal plasma; PBS: Phosphate-buffered saline; PCB28: 2,4,4'-Trichlorobiphenyl; PEF: Photoelectro-Fenton; PET: Polyethylene terephthalate; $\mathrm{pK}_{\mathrm{a}}$ : Negative decadic logarithm of the acid dissociation constant; PVC: Polyvinyl chloride; PMS: Peroxymonosulfate; PS: Peroxydisulfate, persulfate; R: Arginine; SHE: Standard hydrogen electrode; SR: Sulfate radical; STX: Saxitoxin; $t_{1 / 2}$ : Half-life; TDI: Total daily intake; US EPA: United States Environmental Protection Agency; UV: Ultraviolet; Vis: Visible; WHO: World Health Organization; Y: Tyrosine.
\end{abstract}

\section{Acknowledgements}

Not applicable.

\section{Disclaimer}

Any opinions in this article only reflect the authors'views and the European Union's Research Executive Agency is not responsible for any use that may be made of the information it contains.

\section{Authors' contributions}

MS performed the literature research and drafted the manuscript; LB revised the text. Both authors read and approved the final manuscript.

\section{Funding}

This research received funding from the European Union's Horizon 2020 research and innovation program under the Marie Skłodowska-Curie Grant agreement No. 722493 NaToxAq and No. 857560 CETOCOEN EXCELLENCE Teaming 2 project. The RECETOX Research infrastructure was further supported by the Czech Ministry of Education, Youth and Sports (LM2018121; CZ0 2.1.01/0.0/0.0/18_046/0015975).

\section{Availability of data and materials}

Not applicable.

\section{Ethics approval and consent to participate}

Not applicable.

\section{Consent for publication}

Not applicable.

\section{Competing interests}

The authors declare that they have no competing interests.

Received: 19 April 2020 Accepted: 15 June 2020

Published online: 08 July 2020

\section{References}

1. Skulberg OM, Carmichael WW, Codd GA, Skulberg R (1993) Taxonomy of toxic cyanophyceae (Cyanobacteria). In: Falconer IR (ed) Algal toxins in seafood and drinking water. Academic Press, London, pp 145-164

2. Newcombe G (2009) International guidance manual for the management of toxic cyanobacteria. Global Water Research Coalition

3. Durai $P$, Batool M, Choi S (2015) Structure and effects of cyanobacterial lipopolysaccharides. Mar Drugs 13:4217-4230. https://doi.org/10.3390/ md13074217

4. Mantzouki E, Visser PM, Bormans M, lbelings BW (2016) Understanding the key ecological traits of cyanobacteria as a basis for their management and control in changing lakes. Aquat Ecol 50:333-350. https://doi.org/10.1007/s10452-015-9526-3

5. Codd GA, Meriluoto J, Metcalf JS (2016) Introduction. In: Meriluoto J, Spoof L, Codd GA (eds) Handbook of cyanobacterial monitoring and cyanotoxin analysis. Wiley, Hoboken, pp 1-8

6. Buratti FM, Manganelli M, Vichi S et al (2017) Cyanotoxins: producing organisms, occurrence, toxicity, mechanism of action and human health toxicological risk evaluation. Arch Toxicol 91:1049-1130. https:// doi.org/10.1007/s00204-016-1913-6

7. Machado J, Campos A, Vasconcelos V, Freitas M (2017) Effects of microcystin-LR and cylindrospermopsin on plant-soil systems: a review of their relevance for agricultural plant quality and public health. Environ Res 153:191-204. https://doi.org/10.1016/j.envres.2016.09.015

8. Ibelings BW, Bormans M, Fastner J, Visser PM (2016) CYANOCOST special issue on cyanobacterial blooms: synopsis - a critical review of the management options for their prevention, control and mitigation. Aquat Ecol 50:595-605. https://doi.org/10.1007/s10452-016-9596-x

9. Westrick JA, Szlag DC, Southwell BJ, Sinclair J (2010) A review of cyanobacteria and cyanotoxins removal/inactivation in drinking water treatment. Anal Bioanal Chem 397:1705-1714. https://doi.org/10.1007/ s00216-010-3709-5

10. He X, Liu Y-L, Conklin A et al (2016) Toxic cyanobacteria and drinking water: impacts, detection, and treatment. Harmful Algae 54:174-193. https://doi.org/10.1016/j.hal.2016.01.001

11. Chorus I (2005) Water safety plans. In: Huisman J, Matthijs HCP, Visser PM (eds) Harmful cyanobacteria. Springer, Dordrecht, pp 201-227

12. Ho L, Sawade E, Newcombe G (2012) Biological treatment options for cyanobacteria metabolite removal-a review. Water Res 46:1536-1548. https://doi.org/10.1016/j.watres.2011.11.018

13. Lawton LA, Robertson PKJ (1999) Physico-chemical treatment methods for the removal of microcystins (cyanobacterial hepatotoxins) from potable waters. Chem Soc Rev 28:217-224. https://doi.org/10.1039/ A8054161

14. Rodríguez E, Onstad GD, Kull TPJ et al (2007) Oxidative elimination of cyanotoxins: comparison of ozone, chlorine, chlorine dioxide and permanganate. Water Res 41:3381-3393. https://doi.org/10.1016/J.WATRE S.2007.03.033

15. Meriluoto J, Spoof L, Codd GA (2016) Handbook of cyanobacterial monitoring and cyanotoxin analysis. Wiley, Chichester

16. Catherine A, Bernard C, Spoof L, Bruno M (2016) Microcystins and nodularins. In: Meriluoto J, Spoof L, Codd GA (eds) Handbook of cyanobacterial monitoring and cyanotoxin analysis. Wiley, Chichester, pp 107-126

17. Ministry of Health (2017) Guidelines for drinking-water quality management for New Zealand, 3rd edn. Ministry of Health, Wellington

18. Kokociński M, Cameán AM, Carmeli S et al (2016) Cylindrospermopsin and congeners. In: Meriluoto J, Spoof L, Codd GA (eds) Handbook of cyanobacterial monitoring and cyanotoxin analysis. Wiley, Hoboken, pp 127-137

19. Onstad GD, Strauch S, Meriluoto J et al (2007) Selective oxidation of key functional groups in cyanotoxins during drinking water ozonation. Environ Sci Technol 41:4397-4404. https://doi.org/10.1021/es0625327

20. Bruno M, Ploux O, Metcalf JS et al (2016) Anatoxin-a, Homoanatoxin$a$, and natural analogues. In: Meriluoto J, Spoof L, Codd GA (eds) Handbook of cyanobacterial monitoring and cyanotoxin analysis. Wiley, Hoboken, pp 138-147

21. Ballot A, Bernard C, Fastner J (2016) Saxitoxin and analogues. In: Meriluoto J, Spoof L, Codd GA (eds) Handbook of cyanobacterial monitoring and cyanotoxin analysis. Wiley, Hoboken, pp 148-154

22. Ploux O, Combes A, Eriksson J, Metcalf JS (2016) B-N-Methylamino-Lalanine and (S)-2,4-diaminobutyric acid. In: Meriluoto J, Spoof L, Codd GA (eds) Handbook of cyanobacterial monitoring and cyanotoxin analysis. Wiley, Hoboken, pp 160-164

23. Carmichael WW (1992) Cyanobacteria secondary metabolites-the cyanotoxins. J Appl Bacteriol 72:445-459. https://doi. org/10.1111/j.1365-2672.1992.tb01858.x

24. Griffiths DJ, Saker ML (2003) The Palm Island mystery disease 20 years on: a review of research on the cyanotoxin cylindrospermopsin. Environ Toxicol 18:78-93. https://doi.org/10.1002/tox.10103

25. Carmichael WW, Azevedo SM, An JS et al (2001) Human fatalities from cyanobacteria: chemical and biological evidence for cyanotoxins. Environ Health Perspect 109:663-668 
26. Brooks BW, Lazorchak JM, Howard MDA et al (2016) Are harmful algal blooms becoming the greatest inland water quality threat to public health and aquatic ecosystems? Environ Toxicol Chem 35:6-13. https:// doi.org/10.1002/etc.3220

27. Svirčev Z, Drobac D, Tokodi N et al (2016) Lessons from the Užice case. In: Meriluoto J, Spoof L, Codd GA (eds) Handbook of cyanobacterial monitoring and cyanotoxin analysis. Wiley, Hoboken, pp 298-308

28. Fitzsimmons EG (2014) Tap water ban for toledo residents. New York Times

29. Wilson E (2014) Danger from microcystins in toledo water unclear Chem Eng News 92:9

30. WHO (2003) Cyanobacterial toxins: microcystin-LR in drinking-water. Background document for preparation of WHO guidelines for drinkingwater quality. World Health Organization, Geneva

31. Drinking-water quality guidelines. https://www.who.int/water_sanit ation health/water-quality/guidelines/en/. Accessed 27 Mar 2020

32. Chorus I (2012) Current approaches to Cyanotoxin risk assessment, risk management and regulations in different countries. Federal Environment Agency, Dessau-Roßlau

33. Schwarzenbach RP, Gschwend PM, Imboden DM (2002) Indirect photolysis: reactions with photooxidants in natural waters and in the atmosphere. Environmental organic chemistry. Wiley, Hoboken, pp 655-686

34. von Sonntag C, von Gunten U (2012) Reactions of hydroxyl and peroxyl radicals. Chemistry of ozone in water and wastewater treatment: from basic principles to applications. IWA Publishing, London, pp 225-248

35. Zhang B-T, Zhang Y, Teng Y, Fan M (2015) Sulfate radical and its application in decontamination technologies. Crit Rev Environ Sci Technol 45:1756-1800. https://doi.org/10.1080/10643389.2014.970681

36. Antoniou MG, de la Cruz AA, Dionysiou DD (2010) Degradation of microcystin-LR using sulfate radicals generated through photolysis, thermolysis and e-transfer mechanisms. Appl Catal B Environ 96:290-298. https://doi.org/10.1016/J.APCATB.2010.02.013

37. Chen Y-T, Chen W-R, Lin T-F (2018) Oxidation of cyanobacterial neurotoxin beta- $N$-methylamino-L-alanine (BMAA) with chlorine, permanganate, ozone, hydrogen peroxide and hydroxyl radical. Water Res 142:187-195. https://doi.org/10.1016/J.WATRES.2018.05.056

38. Park J-A, Yang B, Park C et al (2017) Oxidation of microcystin-LR by the Fenton process: kinetics, degradation intermediates, water quality and toxicity assessment. Chem Eng J 309:339-348. https://doi.org/10.1016/j. cej.2016.10.083

39. Tak S-Y, Kim M-K, Lee J-E et al (2018) Degradation mechanism of anatoxin-a in UV-C/ $\mathrm{H}_{2} \mathrm{O}_{2}$ reaction. Chem Eng J 334:1016-1022. https:// doi.org/10.1016/J.CEJ.2017.10.081

40. He X, de la Cruz AA, Dionysiou DD (2013) Destruction of cyanobacterial toxin cylindrospermopsin by hydroxyl radicals and sulfate radicals using UV-254 nm activation of hydrogen peroxide, persulfate and peroxymonosulfate. J Photochem Photobiol A Chem 251:160-166. https://doi. org/10.1016/J.JPHOTOCHEM.2012.09.017

41. He X, de la Cruz AA, Hiskia A et al (2015) Destruction of microcystins (cyanotoxins) by UV-254 nm-based direct photolysis and advanced oxidation processes (AOPs): influence of variable amino acids on the degradation kinetics and reaction mechanisms. Water Res 74:227-238. https://doi.org/10.1016/J.WATRES.2015.02.011

42. von Sonntag C, von Gunten U (2012) Chemistry of ozone in water and wastewater treatment: from basic principles to applications. IWA Publishing, London

43. Von Gunten U (2003) Ozonation of drinking water: part I. Oxidation kinetics and product formation. Water Res 37:1443-1467. https://doi. org/10.1016/S0043-1354(02)00457-8

44. Al Momani F (2007) Degradation of cyanobacteria anatoxin-a by advanced oxidation processes. Sep Purif Technol 57:85-93. https://doi. org/10.1016/J.SEPPUR.2007.03.008

45. Al Momani F, Smith DW, Gamal El-Din M (2008) Degradation of cyanobacteria toxin by advanced oxidation processes. J Hazard Mater 150:238-249. https://doi.org/10.1016/j.jhazmat.2007.04.087

46. Yan S, Jia A, Merel S et al (2016) Ozonation of cylindrospermopsin (cyanotoxin): degradation mechanisms and cytotoxicity assessments. Environ Sci Technol 50:1437-1446. https://doi.org/10.1021/acs. est. 5 b0 04540
47. Orr PT, Jones GJ Hamilton GR (2004) Removal of saxitoxins from drinking water by granular activated carbon, ozone and hydrogen peroxide-implications for compliance with the Australian drinking water guidelines. Water Res 38:4455-4461. https://doi.org/10.1016/J.WATRE S.2004.08.024

48. Bober B, Pudas K, Lechowski Z, Bialczyk J (2008) Degradation of microcystin-LR by ozone in the presence of Fenton reagent. J Environ Sci Health A Tox Hazard Subst Environ Eng 43:186-190. https://doi. org/10.1080/10934520701781582

49. Wu C-C, Huang W-J, Ji B-H (2015) Degradation of cyanotoxin cylindrospermopsin by $\mathrm{TiO}_{2}$-assisted ozonation in water. J Environ Sci Health A Tox Hazard Subst Environ Eng 50:1116-1126. https://doi. org/10.1080/10934529.2015.1047664

50. Schwarzenbach RP, Gschwend PM, Imboden DM (2002) Direct photolysis. Environmental organic chemistry. Wiley, Hoboken, pp 611-654

51. Stevens DK, Krieger RI (1991) Stability studies on the cyanobacterial nicotinic alkaloid anatoxin-A. Toxicon 29:167-179. https://doi. org/10.1016/0041-0101(91)90101-V

52. Wörmer L, Huerta-Fontela M, Cirés S et al (2010) Natural photodegradation of the cyanobacterial toxins microcystin and cylindrospermopsin. Environ Sci Technol 44:3002-3007. https://doi.org/10.1021/es9036012

53. Mazur-Marzec H, Meriluoto J, Pliński M (2006) The degradation of the cyanobacterial hepatotoxin nodularin (NOD) by UV radiation. Chemosphere 65:1388-1395. https://doi.org/10.1016/J.CHEMOSPHER E.2006.03.072

54. Afzal A, Oppenländer T, Bolton JR, El-Din MG (2010) Anatoxin-a degradation by advanced oxidation processes: vacuum-UV at $172 \mathrm{~nm}$, photolysis using medium pressure UV and UV/ $\mathrm{H}_{2} \mathrm{O}_{2}$. Water Res 44:278-286. https://doi.org/10.1016/J.WATRES.2009.09.021

55. Moon B-R, Kim T-K, Kim M-K et al (2017) Degradation mechanisms of Microcystin-LR during UV-B photolysis and UV/ $\mathrm{H}_{2} \mathrm{O}_{2}$ processes: byproducts and pathways. Chemosphere 185:1039-1047. https://doi. org/10.1016/J.CHEMOSPHERE.2017.07.104

56. Chang J, Chen Z, Wang Z et al (2015) Oxidation of microcystin-LR in water by ozone combined with UV radiation: the removal and degradation pathway. Chem Eng J 276:97-105. https://doi.org/10.1016/J. CEJ.2015.04.070

57. Liu Y, Ren J, Wang X, Fan Z (2016) Mechanism and reaction pathways for microcystin-LR degradation through $\mathrm{UV} / \mathrm{H}_{2} \mathrm{O}_{2}$ treatment. PLOS ONE 11:e0156236

58. Tsuji K, Naito S, Kondo F et al (1994) Stability of microcystins from cyanobacteria: effect of light on decomposition and isomerization. Environ Sci Technol 28:173-177. https://doi.org/10.1021/es00050a024

59. Gajdek P, Bober B, Mej E, Bialczyk J (2004) Sensitised decomposition of microcystin-LR using UV radiation. J Photochem Photobiol B Biol 76:103-106. https://doi.org/10.1016/J.JPHOTOBIOL.2004.06.001

60. Verma S, Sillanpää M (2015) Degradation of anatoxin-a by UV-C LED and UV-C LED/ $\mathrm{H}_{2} \mathrm{O}_{2}$ advanced oxidation processes. Chem Eng J 274:274-281. https://doi.org/10.1016/J.CEJ.2015.03.128

61. Song W, Yan S, Cooper WJ et al (2012) Hydroxyl radical oxidation of cylindrospermopsin (cyanobacterial toxin) and its role in the photochemical transformation. Environ Sci Technol 46:12608-12615. https:// doi.org/10.1021/es302458h

62. Chiswell RK, Shaw GR, Eaglesham G et al (1999) Stability of cylindrospermopsin, the toxin from the cyanobacterium, Cylindrospermopsis raciborskii: effect of $\mathrm{pH}$, temperature, and sunlight on decomposition. Environ Toxicol 14:155-161. https://doi.org/10.1002/(SICI)15227278(199902)14:1\%3c155:AID-TOX20\%3e3.0.CO;2-Z

63. Adamski M, Żmudzki P, Chrapusta E et al (2016) Characterization of cylindrospermopsin decomposition products formed under irradiation conditions. Algal Res 18:1-6. https://doi.org/10.1016/J.ALGAL .2016 .05 .027

64. Zhang X, He J, Xiao S, Yang X (2019) Elimination kinetics and detoxification mechanisms of microcystin-LR during UV/chlorine process. Chemosphere 214:702-709. https://doi.org/10.1016/J.CHEMOSPHER E.2018.09.162

65. Park J-A, Yang B, Jang M et al (2019) Oxidation and molecular properties of microcystin-LR, microcystin-RR and anatoxin-a using UV-lightemitting diodes at $255 \mathrm{~nm}$ in combination with $\mathrm{H}_{2} \mathrm{O}_{2}$. Chem Eng J 366:423-432. https://doi.org/10.1016/J.CEJ.2019.02.101 
66. Liu X, Chen Z, Zhou N et al (2010) Degradation and detoxification of microcystin-LR in drinking water by sequential use of UV and ozone. J Environ Sci 22:1897-1902. https://doi.org/10.1016/S1001 $-0742(09) 60336-3$

67. Duan X, Sanan T, de la Cruz A et al (2018) Susceptibility of the algal toxin microcystin-LR to UV/Chlorine process: comparison with chlorination. Environ Sci Technol 52:8252-8262. https://doi.org/10.1021/acs. est.8b00034

68. Park J-A, Yang B, Kim J-H et al (2018) Removal of microcystin-LR using UV-assisted advanced oxidation processes and optimization of photoFenton-like process for treating Nak-Dong River water, South Korea. Chem Eng J 348:125-134. https://doi.org/10.1016/J.CEJ.2018.04.190

69. He X, Zhang G, de la Cruz AA et al (2014) Degradation mechanism of cyanobacterial toxin cylindrospermopsin by hydroxyl radicals in homogeneous UV/ $\mathrm{H}_{2} \mathrm{O}_{2}$ process. Environ Sci Technol 48:4495-4504. https:// doi.org/10.1021/es403732s

70. Ochando-Pulido JM, Hodaifa G, Víctor-Ortega MD, Martínez-Ferez A (2013) A novel photocatalyst with ferromagnetic core used for the treatment of olive oil mill effluents from two-phase production process. ScientificWorldJournal 2013:196470. https://doi. org/10.1155/2013/196470

71. Fotiou T, Triantis TM, Kaloudis T et al (2016) Assessment of the roles of reactive oxygen species in the UV and visible light photocatalytic degradation of cyanotoxins and water taste and odor compounds using $\mathrm{C}^{-\mathrm{TiO}_{2}}$. Water Res 90:52-61. https://doi.org/10.1016/J.WATRE S.2015.12.006

72. Chen L, Zhao C, Dionysiou DD, O'Shea KE (2015) $\mathrm{TiO}_{2}$ photocatalytic degradation and detoxification of cylindrospermopsin. J Photochem Photobiol A Chem 307-308:115-122. https://doi.org/10.1016/J.JPHOT OCHEM.2015.03.013

73. Triantis TM, Fotiou T, Kaloudis T et al (2012) Photocatalytic degradation and mineralization of microcystin-LR under UV-A, solar and visible light using nanostructured nitrogen doped $\mathrm{TiO}_{2}$. J Hazard Mater 211-212:196-202. https://doi.org/10.1016/J.JHAZMAT.2011.11.042

74. Pestana CJ, Edwards C, Prabhu R et al (2015) Photocatalytic degradation of eleven microcystin variants and nodularin by $\mathrm{TiO}_{2}$ coated glass microspheres. J Hazard Mater 300:347-353. https://doi.org/10.1016/J. JHAZMAT.2015.07.016

75. Lawton LA, Robertson PKJ, Cornish BJPA et al (2003) Processes influencing surface interaction and photocatalytic destruction of microcystins on titanium dioxide photocatalysts. J Catal 213:109-113. https://doi. org/10.1016/S0021-9517(02)00049-0

76. Pelaez M, de la Cruz AA, O'Shea K et al (2011) Effects of water parameters on the degradation of microcystin-LR under visible light-activated TiO2 photocatalyst. Water Res 45:3787-3796. https://doi.org/10.1016/J. WATRES.2011.04.036

77. Pelaez M, de la Cruz AA, Stathatos E et al (2009) Visible light-activated $\mathrm{N}$-F-codoped $\mathrm{TiO}_{2}$ nanoparticles for the photocatalytic degradation of microcystin-LR in water. Catal Today 144:19-25. https://doi. org/10.1016/J.CATTOD.2008.12.022

78. Zhao C, Pelaez M, Dionysiou DD et al (2014) UV and visible light activated $\mathrm{TiO}_{2}$ photocatalysis of 6-hydroxymethyl uracil, a model compound for the potent cyanotoxin cylindrospermopsin. Catal Today 224:70-76. https://doi.org/10.1016/J.CATTOD.2013.09.042

79. Han C, Pelaez M, Likodimos V et al (2011) Innovative visible light-activated sulfur doped $\mathrm{TiO}_{2}$ films for water treatment. Appl Catal B Environ 107:77-87. https://doi.org/10.1016/J.APCATB.2011.06.039

80. Pelaez M, Falaras P, Likodimos V et al (2016) Use of selected scavengers for the determination of $\mathrm{NF}-\mathrm{TiO}_{2}$ reactive oxygen species during the degradation of microcystin-LR under visible light irradiation. J Mol Catal A Chem 425:183-189. https://doi.org/10.1016/J.MOLCATA.2016.09.035

81. Zhao C, Li D, Liu Y et al (2015) Photocatalytic removal of microcystin-LR by advanced WO3-based nanoparticles under simulated solar light. ScientificWorldJournal 2015:720706. https://doi.org/10.1155/2015/720706

82. Han C, Machala L, Medrik I et al (2017) Degradation of the cyanotoxin microcystin-LR using iron-based photocatalysts under visible light illumination. Environ Sci Pollut Res 24:19435-19443. https://doi. org/10.1007/s11356-017-9566-4

83. Wang S, Ma W, Fang Y et al (2014) Bismuth oxybromide promoted detoxification of cylindrospermopsin under UV and visible light illumination. Appl Catal B Environ 150-151:380-388. https://doi. org/10.1016/J.APCATB.2013.12.016

84. Yanfen $F$, Yingping $H$, Jing $Y$ et al (2011) Unique ability of BiOBr to decarboxylate $d$-Glu and d-MeAsp in the photocatalytic degradation of microcystin-LR in water. Environ Sci Technol 45:1593-1600. https://doi. org/10.1021/es103422j

85. Pinho LX, Azevedo J, Miranda SM et al (2015) Oxidation of microcystinLR and cylindrospermopsin by heterogeneous photocatalysis using a tubular photoreactor packed with different $\mathrm{TiO}_{2}$ coated supports. Chem Eng J 266:100-111. https://doi.org/10.1016/J.CEJ.2014.12.023

86. Lee D-K, Kim S-C, Kim S-J et al (2004) Photocatalytic oxidation of microcystin-LR with $\mathrm{TiO}_{2}$-coated activated carbon. Chem Eng J 102:93-98. https://doi.org/10.1016/J.CEJ.2004.01.027

87. Cornish BJP, Lawton LA, Robertson PK (2000) Hydrogen peroxide enhanced photocatalytic oxidation of microcystin-LR using titanium dioxide. Appl Catal B Environ 25:59-67. https://doi.org/10.1016/S0926 $-3373(99) 00121-6$

88. Bessegato GG, Guaraldo TT, de Brito JF et al (2015) Achievements and trends in photoelectrocatalysis: from environmental to energy applications. Electrocatalysis 6:415-441. https://doi.org/10.1007/s1267 8-015-0259-9

89. Liao W, Zhang Y, Zhang M et al (2013) Photoelectrocatalytic degradation of microcystin- $\mathrm{LR}$ using $\mathrm{Ag} / \mathrm{AgCl} / \mathrm{TiO}_{2}$ nanotube arrays electrode under visible light irradiation. Chem Eng J 231:455-463. https://doi. org/10.1016/J.CEJ.2013.07.054

90. Moreira FC, Boaventura RAR, Brillas E, Vilar VJP (2017) Electrochemical advanced oxidation processes: a review on their application to synthetic and real wastewaters. Appl Catal B Environ 202:217-261. https ://doi.org/10.1016/j.apcatb.2016.08.037

91. Liu J, Hernández SE, Swift S, Singhal N (2018) Estrogenic activity of cylindrospermopsin and anatoxin-a and their oxidative products by Felll-B*/H2O2. Water Res 132:309-319. https://doi.org/10.1016/JWATRE S.2018.01.018

92. Munoz M, Nieto-Sandoval J, Cirés S et al (2019) Degradation of widespread cyanotoxins with high impact in drinking water (microcystins, cylindrospermopsin, anatoxin-a and saxitoxin) by CWPO. Water Res 163:114853. https://doi.org/10.1016/J.WATRES.2019.114853

93. Zhong Y, Jin X, Qiao R et al (2009) Destruction of microcystin-RR by Fenton oxidation. J Hazard Mater 167:1114-1118. https://doi.org/10.1016/J. JHAZMAT.2009.01.117

94. Jung YS, Lim WT, Park J, Kim Y (2009) Effect of pH on fenton and fenton-like oxidation. Environ Technol 30:183-190. https://doi. org/10.1080/09593330802468848

95. Fang Y-F, Chen D-X, Huang Y-P et al (2011) Heterogeneous fenton photodegradation of microcystin-LR with visible light irradiation. Chinese J Anal Chem 39:540-543. https://doi.org/10.1016/S1872-2040(10)60433 $-1$

96. Lee H, Lee H-J, Sedlak DL, Lee C (2013) pH-Dependent reactivity of oxidants formed by iron and copper-catalyzed decomposition of hydrogen peroxide. Chemosphere 92:652-658. https://doi.org/10.1016/J. CHEMOSPHERE.2013.01.073

97. Gajdek P, Lechowski Z, Bochnia T, Kępczyński M (2001) Decomposition of microcystin-LR by Fenton oxidation. Toxicon 39:1575-1578. https:// doi.org/10.1016/S0041-0101(01)00139-8

98. Zhou S, Yu Y, Sun J et al (2018) Oxidation of microcystin-LR by copper (II) coupled with ascorbic acid: kinetic modeling towards generation of $\mathrm{H}_{2} \mathrm{O}_{2}$. Chem Eng J 333:443-450. https://doi.org/10.1016/J. CEJ.2017.09.166

99. Bandala ER, Martínez D, Martínez E, Dionysiou DD (2004) Degradation of microcystin-LR toxin by Fenton and Photo-Fenton processes. Toxicon 43:829-832. https://doi.org/10.1016/j.toxicon.2004.03.013

100. de Freitas AM, Sirtori C, Lenz CA, Peralta Zamora PG (2013) MicrocystinLR degradation by solar photo-Fenton, UV-A/photo-Fenton and UV-C/ $\mathrm{H}_{2} \mathrm{O}_{2}$ : a comparative study. Photochem Photobiol Sci 12:696-702. https ://doi.org/10.1039/C2PP25233C

101. MaY-S (2012) Short review: current trends and future challenges in the application of sono-Fenton oxidation for wastewater treatment. Sustain Environ Res 22:271-278

102. Karci A, Wurtzler EM, de la Cruz AA et al (2018) Solar photo-Fenton treatment of microcystin-LR in aqueous environment: transformation 
products and toxicity in different water matrices. J Hazard Mater 349:282-292. https://doi.org/10.1016/J.JHAZMAT.2017.12.071

103. Wang F, Wu Y, Gao Y et al (2016) Effect of humic acid, oxalate and phosphate on Fenton-like oxidation of microcystin-LR by nanoscale zerovalent iron. Sep PurifTechnol 170:337-343. https://doi.org/10.1016/J. SEPPUR.2016.06.046

104. Scholtz V, Pazlarova J, Souskova H et al (2015) Nonthermal plasma-a tool for decontamination and disinfection. Biotechnol Adv 33:11081119. https://doi.org/10.1016/J.BIOTECHADV.2015.01.002

105. Meichsner J, Schmidt M, Schneider R, Wagner HE (2013) Introduction. Nonthermal plasma chemistry and physics. CRC Press, Boca Raton, pp $1-6$

106. Meichsner J, Schmidt M, Schneider R, Wagner HE (2013) Selected applications. Nonthermal plasma chemistry and physics. CRC Press, Boca Raton, pp 285-406

107. Banaschik R, Lukes P, Miron C et al (2017) Fenton chemistry promoted by sub-microsecond pulsed corona plasmas for organic micropollutant degradation in water. Electrochim Acta 245:539-548. https://doi. org/10.1016/J.ELECTACTA.2017.05.121

108. Jo J-O, Jwa E, Mok Y-S (2016) Decomposition of aqueous anatoxin-a using underwater dielectric barrier discharge plasma created in a porous ceramic tube. J Korean Soc Water Wastewater 30:167-177. https ://doi.org/10.11001/jksww.2016.30.2.167

109. Zhang H, Huang Q, Ke Z et al (2012) Degradation of microcystin-LR in water by glow discharge plasma oxidation at the gas-solution interface and its safety evaluation. Water Res 46:6554-6562. https://doi. org/10.1016/j.watres.2012.09.041

110. Banaschik R, Jablonowski H, Bednarski PJ, Kolb JF (2018) Degradation and intermediates of diclofenac as instructive example for decomposition of recalcitrant pharmaceuticals by hydroxyl radicals generated with pulsed corona plasma in water. J Hazard Mater 342:651-660. https:// doi.org/10.1016/J.JHAZMAT.2017.08.058

111. Xin Q, Zhang Y, Wu K (2013) Degradation of microcystin-LR by gasliquid interfacial discharge plasma. Plasma Sci Technol 15:1221

112. Xin Q, Zhang Y, Wu KB (2013) Mn-doped carbon xerogels as catalyst in the removal of microcystin-LR by water-surface discharge plasma. J Environ Sci Health A Toxic Hazard Subst Environ Eng 48:293-299. https ://doi.org/10.1080/10934529.2013.726833

113. Nisol B, Watson S, Leblanc Y et al (2019) Cold plasma oxidation of harmful algae and associated metabolite BMAA toxin in aqueous suspension. Plasma Process Polym 16:1800137. https://doi.org/10.1002/ ppap.201800137

114. Xin Q, Zhang Y, Li Z et al (2015) Mn/Ti-doped carbon xerogel for efficient catalysis of microcystin-LR degradation in the water surface discharge plasma reactor. Environ Sci Pollut Res 22:17202-17208. https ://doi.org/10.1007/s11356-015-4956-y

115. Zhang Y, Wei H, Xin Q et al (2016) Process optimization for microcystinLR degradation by response surface methodology and mechanism analysis in gas-liquid hybrid discharge system. J Environ Manage 183:726-732. https://doi.org/10.1016/j.jenvman.2016.09.030

116. Pekárek S (2012) Experimental study of surface dielectric barrier discharge in air and its ozone production. J Phys D Appl Phys 45:75201. https://doi.org/10.1088/0022-3727/45/7/075201

117. Matzek LW, Carter KE (2016) Activated persulfate for organic chemical degradation: a review. Chemosphere 151:178-188. https://doi. org/10.1016/J.CHEMOSPHERE.2016.02.055

118. Wacławek S, Lutze HV, Grübel K et al (2017) Chemistry of persulfates in water and wastewater treatment: a review. Chem Eng J 330:44-62. https://doi.org/10.1016/J.CEJ.2017.07.132

119. Son G, Lee H (2016) Methylene blue removal by submerged plasma irradiation system in the presence of persulfate. Environ Sci Pollut Res 23:15651-15656. https://doi.org/10.1007/s11356-016-6759-1

120. Bakheet B, Islam MA, Beardall J et al (2018) Electrochemical inactivation of Cylindrospermopsis raciborskii and removal of the cyanotoxin cylindrospermopsin. J Hazard Mater 344:241-248. https://doi.org/10.1016/J. JHAZMAT.2017.10.024

121. Yang Y, Jiang J, Lu X et al (2015) Production of sulfate radical and hydroxyl radical by reaction of ozone with peroxymonosulfate: a novel advanced oxidation process. Environ Sci Technol 49:7330-7339. https:// doi.org/10.1021/es506362e
122. Lou X, Wu L, Guo Y et al (2014) Peroxymonosulfate activation by phosphate anion for organics degradation in water. Chemosphere 117:582-585. https://doi.org/10.1016/J.CHEMOSPHERE.2014.09.046

123. Antoniou MG, de la Cruz AA, Dionysiou DD (2010) Intermediates and reaction pathways from the degradation of microcystin-LR with sulfate radicals. Environ Sci Technol 44:7238-7244. https://doi.org/10.1021/ es 1000243

124. Verma S, Nakamura S, Sillanpää M (2016) Application of UV-C LED activated PMS for the degradation of anatoxin-a. Chem Eng J 284:122-129. https://doi.org/10.1016/J.CEJ.2015.08.095

125. He X, de la Cruz AA, O'Shea KE, Dionysiou DD (2014) Kinetics and mechanisms of cylindrospermopsin destruction by sulfate radicalbased advanced oxidation processes. Water Res 63:168-178. https:// doi.org/10.1016/J.WATRES.2014.06.004

126. Antoniou MG, Boraei I, Solakidou M et al (2018) Enhancing photocatalytic degradation of the cyanotoxin microcystin-LR with the addition of sulfate-radical generating oxidants. J Hazard Mater 360:461-470. https ://doi.org/10.1016/J.JHAZMAT.2018.07.111

127. Fang G, Gao J, Dionysiou DD et al (2013) Activation of persulfate by quinones: free radical reactions and implication for the degradation of PCBs. Environ Sci Technol 47:4605-4611. https://doi.org/10.1021/es400 $262 n$

128. Sanz Lobón G, Yepez A, Garcia LF et al (2017) Efficient electrochemical remediation of microcystin-LR in tap water using designerTiO(2)@ carbon electrodes. Sci Rep 7:41326. https://doi.org/10.1038/srep41326

129. Tran N, Drogui P (2013) Electrochemical removal of microcystin-LR from aqueous solution in the presence of natural organic pollutants. J Environ Manage 114:253-260. https://doi.org/10.1016/J.JENVM AN.2012.10.009

130. Zhou S, Bu L, Yu Y et al (2016) A comparative study of microcystin-LR degradation by electrogenerated oxidants at BDD and MMO anodes. Chemosphere 165:381-387. https://doi.org/10.1016/J.CHEMOSPHER E.2016.09.057

131. Santos PVF, Lopes IC, Diculescu VC et al (2011) Redox mechanisms of nodularin and chemically degraded nodularin. Electroanalysis 23:2310-2319. https://doi.org/10.1002/elan.201100246

132. Liang W, Qu J, Wang K et al (2008) Electrochemical degradation of cyanobacterial toxin microcystin-LR using $\mathrm{Ti} / \mathrm{RuO}_{2}$ electrodes in a continuous tubular reactor. Environ Eng Sci 25:635-642. https://doi. org/10.1089/ees.2006.0273

133. Zhang C, Fu D, Gu Z (2009) Degradation of microcystin-RR using borondoped diamond electrode. J Hazard Mater 172:847-853. https://doi. org/10.1016/J.JHAZMAT.2009.07.071

134. Zhou S, Bu L, Shi Z et al (2018) Electrochemical inactivation of Microcystis aeruginosa using BDD electrodes: kinetic modeling of microcystins release and degradation. J Hazard Mater 346:73-81. https://doi. org/10.1016/J.JHAZMAT.2017.12.023

135. Zhang $Y$, Zhang $Y$, Yang $N$ et al (2013) Electrochemical degradation and mechanistic analysis of microcystin-LR. J Chem Technol Biotechnol 88:1529-1537. https://doi.org/10.1002/jctb.3999

136. Gagol M, Przyjazny A, Boczkaj G (2018) Wastewater treatment by means of advanced oxidation processes based on cavitation - a review. Chem Eng J 338:599-627. https://doi.org/10.1016/J.CEJ.2018.01.049

137. Song W, de la Cruz AA, Rein K, O'Shea KE (2006) Ultrasonically induced degradation of microcystin-LR and -RR: identification of products, effect of $\mathrm{pH}$, formation and destruction of peroxides. Environ Sci Technol 40:3941-3946. https://doi.org/10.1021/es0521730

138. Song W, Teshiba T, Rein K, O'Shea KE (2005) Ultrasonically induced degradation and detoxification of microcystin-LR (cyanobacterial toxin). Environ Sci Technol 39:6300-6305. https://doi.org/10.1021/es048350z

139. Shi J, Han X, Zhu Z, Deng H (2012) Identification of cytotoxicity intermediate products and degradation pathways for microcystins using lowfrequency ultrasonic irradiation. Water Air Soil Pollut 223:5027-5038. https://doi.org/10.1007/s11270-012-1254-x

140. Ma B, Chen Y, Hao H et al (2005) Influence of ultrasonic field on microcystins produced by bloom-forming algae. Colloids Surf B Biointerfaces 41:197-201. https://doi.org/10.1016/J.COLSURFB.2004.12.010

141. Choppin G, Liljenzin J-O, Rydberg J, Ekberg C (2013) Absorption of nuclear radiation. Radiochemistry and nuclear chemistry. Elsevier, Amsterdam, pp 163-208 
142. Choppin G, Liljenzin J-O, Rydberg J, Ekberg C (2013) Radiation effects on matter. Radiochemistry and nuclear chemistry. Elsevier, Amsterdam, pp 209-237

143. Song W, Xu T, Cooper WJ et al (2009) Radiolysis studies on the destruction of microcystin-LR in aqueous solution by hydroxyl radicals. Environ Sci Technol 43:1487-1492. https://doi.org/10.1021/es802282n

144. Zhang JB, Zheng Z, Yang GJ, Zhao YF (2007) Degradation of microcystin by gamma irradiation. Nucl Instruments Methods Phys Res Sect A Accel Spectrom Detect Assoc Equip 580:687-689. https://doi.org/10.1016/J. NIMA.2007.05.109

145. Liu S, Zhao Y, Ma F et al (2015) Control of Microcystis aeruginosa growth and associated microcystin cyanotoxin remediation by electron beam irradiation (EBI). RSC Adv 5:31292-31297. https://doi.org/10.1039/ C5RA00430F

146. Miklos DB, Remy C, Jekel M et al (2018) Evaluation of advanced oxidation processes for water and wastewater treatment-a critical review. Water Res 139:118-131. https://doi.org/10.1016/J.WATRES.2018.03.042

147. Rosenfeldt EJ, Linden KG, Canonica S, von Gunten U (2006) Comparison of the efficiency of $\mathrm{OH}$ radical formation during ozonation and the advanced oxidation processes $\mathrm{O} 3 / \mathrm{H}_{2} \mathrm{O}_{2}$ and $\mathrm{UV} / \mathrm{H}_{2} \mathrm{O}_{2}$. Water Res 40:3695-3704. https://doi.org/10.1016/J.WATRES.2006.09.008

148. Liu J, Ye J-S, Ou H-S, Lin J (2017) Effectiveness and intermediates of microcystin-LR degradation by UV/H2O2 via $265 \mathrm{~nm}$ ultraviolet lightemitting diodes. Environ Sci Pollut Res Int 24:4676-4684. https://doi. org/10.1007/s11356-016-8148-1

149. Schneider O, Liang R, Bragg L et al (2019) Photocatalytic degradation of microcystins by $\mathrm{TiO}_{2}$ using UV-LED controlled periodic illumination. Catalysts 9:181. https://doi.org/10.3390/catal9020181

150. WHO (2005) Bromate in drinking-water. Background document for development of WHO guidelines for drinking-water quality. World Health Organization, Geneva
151. WHO (2005) Trihalomethanes in drinking-water. Background document for development of WHO guidelines for drinking-water quality. World Health Organization, Geneva

152. WHO (2016) Perchlorate in drinking-water. Background document for development of WHO guidelines for drinking-water quality. World Health Organization, Geneva

153. von Gunten U, Hoigne J (1994) Bromate formation during ozonization of bromide-containing waters: interaction of ozone and hydroxyl radical reactions. Environ Sci Technol 28:1234-1242. https://doi. org/10.1021/es00056a009

154. Lutze $H$ (2013) Sulfate radical based oxidation in water treatment (Doctoral Dissertation). University of Duisburg-Essen, Department of Instrumental Analytical Chemistry

155. Rakness KL (2005) Introduction. In: Rakness KL (ed) Ozone in drinking water treatment: process design, operation, and optimization, 1st edn. American Water Works Association, Denver, pp 1-16

156. Lawton LA, Robertson PKJ, Cornish BJPA, Jaspars M (1999) Detoxification of microcystins (cyanobacterial hepatotoxins) using $\mathrm{TiO}_{2}$ photocatalytic oxidation. Environ Sci Technol 33:771-775. https://doi. org/10.1021/es9806682

157. Banaschik R, Lukes P, Jablonowski H et al (2015) Potential of pulsed corona discharges generated in water for the degradation of persistent pharmaceutical residues. Water Res 84:127-135. https://doi. org/10.1016/J.WATRES.2015.07.018

158. WHO (2004) Sulfate in drinking-water. Background document for development of WHO guidelines for drinking-water quality. World Health Organization, Geneva

\section{Publisher's Note}

Springer Nature remains neutral with regard to jurisdictional claims in published maps and institutional affiliations.

\section{Submit your manuscript to a SpringerOpen ${ }^{\circ}$ journal and benefit from:}

- Convenient online submission

- Rigorous peer review

- Open access: articles freely available online

- High visibility within the field

- Retaining the copyright to your article

Submit your next manuscript at $\boldsymbol{\nabla}$ springeropen.com 